\title{
Beyond 17\% Stable Perovskite Solar Module via Polaron Arrange- ment of Tuned Polymeric Hole Transport Layer
}

Narges Yaghoobi Nia, ${ }^{1 *}$ Mahmoud Zendehdel, ${ }^{1,2}$ Mojtaba Abdi-Jalebi, ${ }^{3 *}$ Luigi Angelo Castriotta, ${ }^{1}$ Felix U. Kosasih, ${ }^{4}$ Enrico Lamanna, ${ }^{1}$ Mohammad Mahdi Abolhasani, ${ }^{5,6}$ Zhaoxiang Zheng, ${ }^{1}$ Zahra Andaji-Garmaroudi, ${ }^{7}$ Kamal Asadi, ${ }^{5,8}$ Giorgio Divitini, ${ }^{4}$ Caterina Ducati, ${ }^{4}$ Richard H. Friend ${ }^{7}$ and Aldo Di Carlo ${ }^{1,9,10 *}$

1. Centre for Hybrid and Organic Solar Energy (CHOSE), University of Rome "Tor Vergata", via del Politecnico 1, Rome 00133, Italy.

2. Kimia Solar Research Institute (K.S.R.I), Kimia Solar Company, Kashan, 87137-45868, Iran.

3. Institute for Materials Discovery, University College London, Torrington Place, London WC1E 7JE, United Kingdom.

4. Department of Materials Science \& Metallurgy, University of Cambridge, 27 Charles Babbage Road, Cambridge CB3 0FS, United Kingdom.

5. Max Planck Institute for Polymer Research, Ackermannweg 10, 55128, Mainz, Germany.

6. Chemical Engineering Department, University of Kashan, Kashan, Iran.

7. Cavendish Laboratory, Department of Physics, University of Cambridge, JJ Thomson Avenue, Cambridge CB3 OHE, United Kingdom.

8. Department of Physics, University of Bath, Claverton Down, Bath BA2 7AY, United Kingdom

9. CNR-ISM Istituto di Struttura della Materia, via Fosso del Cavaliere 100, 00133 Rome, Italy.

10. LASE-Laboratory for Advanced Solar Energy, NUST-MISIS, Leninskiy prospect 4, 119049 Moscow (Russia).

ABSTRACT: Operational stability of perovskite solar cells (PSCs) is rapidly becoming one of the pressing bottlenecks for their upscaling and integration of such promising photovoltaic technology. Instability of the hole transport layer (HTL) has been considered as one of the potential origins of short life-time of the PSCs. In this work, by varying the molecular weight (MW) of doped poly(triarylamine)(PTAA) HTL, we improved by one order of magnitude the charge mobility inside the HTL and the charge transfer at the perovskite/HTL interface. We demonstrate that this occurs via the enhancement of polaron delocalization on the polymeric chains through the combined effect of doping strategy and MW tuning. By using high MW PTAA doped combining three different dopant, we demonstrate stable PSCs with typical power conversion efficiencies above $20 \%$, retain more than $90 \%$ of the initial efficiency after 1080 hours thermal stress at $85^{\circ} \mathrm{C}$ and $87 \%$ of initial efficiency after 160 hours exposure against 1 sun light soaking. By using this doping-MW strategy, we realized perovskite solar modules with an efficiency of $17 \%$ on an active area of $43 \mathrm{~cm}^{2}$, keeping above $90 \%$ of the initial efficiency after 800 hours thermal stress at $85^{\circ} \mathrm{C}$. These results, obtained in ambient conditions, pave the way toward the industrialization of PSC-based photovoltaic technology.

\section{Introduction}

Although perovskite solar cells (PSCs) have reached a record Power Conversion Efficiency (PCE) of $25.5 \%$,[1] the research activity to improve the long-term stability and reliability of this photovoltaic technology is only at the beginning, and much of its course goes through the identification and targeting of the weakest elements in the stability chain.[2] Now that temperature-stable perovskite stoichiometry, alongside the standard $\mathrm{CH}_{3} \mathrm{NH}_{3} \mathrm{PbI}_{3}$ (MAPI), have been developed and widely used, the current bottlenecks are the materials used as charge selective layer and their interface with the perovskite active layer. Currently, the most commonly used material for the hole-transport layer (HTL) in high efficiency n-i-p 
perovskite solar cells is Spiro-OMeTAD.[3-5] Jeong et al. recently by using fluorinated isomeric analogs of Spiro-OMeTAD as HTL (Spiro-mF-based PSC), could reach 24.82\% (certified at 24.64\% with 0.3 -volt voltage loss) efficiency for small area devices $\left(0.08 \mathrm{~cm}^{2}\right)$ and efficiency of $22.31 \%$ with an area of $1 \mathrm{~cm}^{2}$ which is among the best published efficiency results.[6] There have been various reports on attempts to substitute it with alternative,[7] cheaper,[8,9] undoped,[10,11] more stable[12] and inorganic materials,[13] yet Spiro-OMeTAD still accounts for the highest PCE published in literature, namely the 23.3\%.[5] Nevertheless, finding a valid alternative to Spiro-OMeTAD is of crucial importance in order to enable the commercialization of perovskite-based photovoltaics, as this material represents one of the most critical elements when it comes to evaluating the thermal stability of the devices. [14] In fact, low glass transition temperature $\left(\mathrm{T}_{\mathrm{g}}\right)$ [15-17] and molecular based structure of Spiro-OMeTAD make an obstacle to pass the standard damp heat tests of devices at $85{ }^{\circ} \mathrm{C}$ and $85 \%$ humidity. Among the various hole transport material (HTM)alternatives, polymers represent a low-cost and versatile option, and have already proven to be valuable candidates for $n-i-p$ perovskite devices.[10] It has been shown that the molecular weight (MW) of the polymeric HTL can affect the performance and/or the stability of the devices, and should therefore be optimized. Generally, MW strongly affects the electrical and mechanical properties of polymers, as demonstrated in numerous studies for poly(3-hexyl-thiophene) (P3HT). In 2003 and then again in 2005, two works by Kline et al. showed the increase in the charge carrier mobility of regio-regular P3HT thin films for organic field effect transistors by increasing the MW of the polymer.[18] The authors justify the results saying that, while lower MW materials exhibit higher crystallinity, the charge transport mechanisms are also dependent on the interconnectivity of the chains of the polymer network, with the low MW films presenting more isolated structures.[19] Observing a similar trend, Neher and coworkers inferred that higher MW P3HT more easily adopts a planar $\pi$-stacked configuration which improves the interchain connections necessary for charge transport, while shorter chains undergo twisting, which hinders the carriers mobility.[20] Interchain interactions have a profound effect on charge transport and optoelectronic properties as well as on stability.[21] As a further note, because of the 'softness' of polymeric materials, charge carriers may interact with local vibrational modes. These interactions result in a distortion of monomers composing the chain, thus lowering the total energy. At the same time, charge will be attracted to the distorted monomer and, if the interaction is strong enough, this may result in charge localization, hence in the formation of a polaron. Polarons affect charge mobility because they alter the effective mass of the charge carriers.[22] Usually, interchain interactions, related to the crystallinity of the layer as well as polymer MW, impact on charged polarons and neutral excitons. Chang et al., experimentally evidenced that increasing the conjugation length of P3HT led to an enhancement of polaron delocalization across the layer.[23] In P3HT the MW and the crystalline quality of the film will influence the degree of delocalization of said polarons, resulting in the aforementioned trend in mobility.[23] In our previous work we have also shown how the MW of P3HT, used as a HTL in PSCs, has an effect on the cell efficiency: specifically, we observed an evident trend of increasing efficiency with increasing MW.[24] Among various conjugated polymers used as HTL in PSCs, PTAA has shown promising performance with the potentiality to achieve the highest open circuit voltage $\left(\mathrm{V}_{\text {oc }}\right)$ among many tested HTLs, because of the high photoluminescence (PL) that perovskites exhibit on it.[25] This is a clear evidence of reduction of non-radiative recombination leading to an increase of the quasi-Fermi level splitting, and consequently to a higher $\mathrm{V}_{\text {oc. }}$ [25] Also for PTAA the relation between performances and MW has been recently discussed, even though with a minor extend with respect to P3HT. Lee and co-workers investigated the effect of tuning the MW of PTAA to increase both mechanical properties of the film and electrical properties of PSCs, revealing that higher MWs exhibit better cohesion and tensile strength.[26] Ko et al investigated the effect of PTAA on aggregation and charge transport in planar PSCs, showing an increase of the PCE by using high MW PTAA (50kDa).[27] Similarly, Zhao et al. extended the analysis to inverted (p-i-n) PSCs using undoped PTAA with different MWs, showing that the $25 \mathrm{kDa}$ polymer resulted in the best performing solar cells.[28] In the n-i-p configuration, PTAA was found to be potentially more stable than Spiro-OMeTAD over the long term and upon thermal stress, even when doped.[29,30] As further proof of the potential of this material, it was also shown that PTAA fluorination may also increase its perfor- 
mance and the stabilized power output in n-i-p structure.[31]

Considering the importance of PTAA in perovskite PV and the lack of a systematic investigation of the impact of MW on the efficiency and stability of the perovskite cells and modules, in this work, for all the aforementioned reasons and the importance that PTAA has in perovskite PVs, we perform a thorough study of the impact of PTAA's MW and doping on the efficiency and thermal stability of n-i-p PSCs. Here we combine the high efficiencies achievable by this architecture with strategies that could enhance the stability of these devices. We demonstrate that an optimized doping strategy of a high MW doped-PTAA permit to increase the efficiency of cells (PCE > 20\%) and large area (active area: $43 \mathrm{~cm}^{2}$ ) modules ( $\mathrm{PCE}=17 \%$ ) keeping at the same a high thermal stability for 1000 hours under $85^{\circ} \mathrm{C}$ and light stability for 800 hours T80 extracted life time and constitutes a big leap forward towards commercialization of the perovskite based solar cells. We should point out that the performance of the module is among the best results published in literature so far, as shown in Figure 1.[10,32-62]

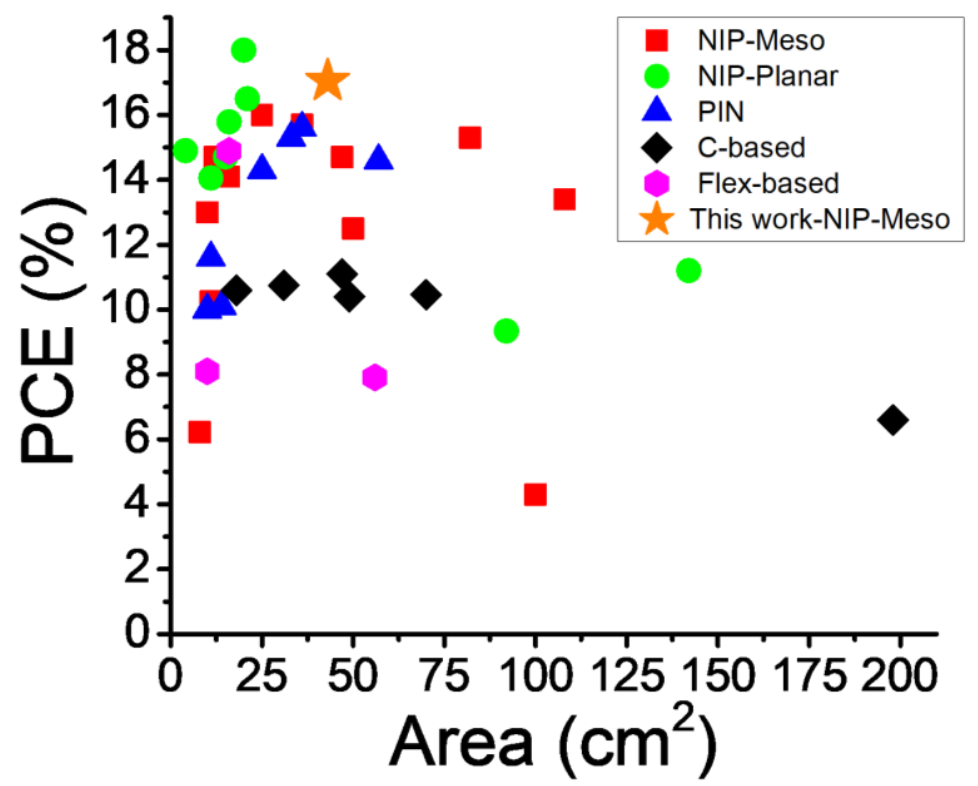

Figure 1. The plot of the highest efficiency modules versus area (aperture or active area in $\mathrm{cm}^{2}$ unit) with different device configurations.

\section{Results}

The photovoltaic performance of small area PSCs using doped-PTAA as HTM namely $10 \mathrm{kDa}$ (LMW), $37 \mathrm{kDa}(\mathrm{MMW})$ and $115 \mathrm{kDa}$ (HMW) were evaluated by current-voltage (JV) measurements under 1 sun AM1.5G solar simulator. The statistical distributions of PCEs of the fabricated small area devices for the three MWs are reported in Figure $\mathbf{2 a}$. As we can clearly see, the PCE increases by increasing the MW of PTAA. The monotonic increase of the PCE as a function of the MW is related to a similar increase of the open-circuit voltage $\left(\mathrm{V}_{\mathrm{OC}}\right)$, short circuit current $\left(\mathrm{J}_{\mathrm{SC}}\right)$ and Fill-Factor $(\mathrm{FF})$, shown in Figure $\mathbf{S 1}$ and Table S1. The photovoltaic parameters for the best devices are reported in Table 1 (see Table S1 for the average values). The champion device for HMW doped-PTAA shows a max PCE of 20\% with very low hysteresis index $(\mathrm{HI}=0.046)$. In addition, the incident photon to converted electron (IPCE) curve and corresponding integrated current density are presented in Figure 2b. The Jsc from IPCE (23.07 $\left.\mathrm{mA} / \mathrm{cm}^{2}\right)$ is in good agreement with Jsc extracted from the JV measurement $\left(22.85 \mathrm{~mA} / \mathrm{cm}^{2}\right)$. The photovoltaic parameters of champion large area device with different MW of doped-PTAA is presented in Table $\mathbf{S 2}$. 
To demonstrate that the enhancement observed for small area cells can be extended to large size devices, we realized a batch of Perovskite Solar Module (PSM) (6 modules/batch) following the fabrication procedure detailed in Experimental section. A $(10 \mathrm{~cm} \times 10 \mathrm{~cm})$ glass/FTO was used to fabricate the module formed by 14 series connected cells with a total active area of 42.8 $\mathrm{cm}^{2}$ and aperture area of $50 \mathrm{~cm}^{2}$. The JV measurement of the champion PSM is represented in Figure 2c with photovoltaic parameters reported in Table 1 and Table 2, while the statistical date for the full batch is reported in Figure $\mathbf{S 2}$ and Table S3. By using doped high MW PTAA we could achieve more than $17 \%$ of PCE on active area, leading to $729.5 \mathrm{~mW}$ of output power at the maximum power point. Interestingly, the module shows very low hysteresis index for the different voltage sweeps. The module achieves Voc, Isc and fill factor of $16.05 \mathrm{~V}, 64.13 \mathrm{~mA}$ and $71 \%$ respectively.

Table1. Photovoltaic parameters of champion small area cell and module using high MW doped-PTAA as HTL.

\begin{tabular}{|c|l|l|l|l|l|}
\hline Sample & Scan Direction & $\mathrm{V}_{\mathrm{oc}}(\mathrm{V})$ & $\mathrm{J}_{\mathrm{sc}}\left(\mathrm{mA} / \mathrm{cm}^{2}\right)$ & $\mathrm{FF}(\%)$ & PCE (\%) \\
\hline $\begin{array}{c}\text { Small area } \\
\left(0.1 \mathrm{~cm}^{2} \text { a.a. }\right)\end{array}$ & Reverse & 1.19 & 22.85 & 73.97 & 20.04 \\
\cline { 2 - 6 } & Forward & 1.16 & 22.61 & 73.12 & 19.12 \\
\hline Sample & Scan Direction & $\mathrm{V}_{\mathrm{oc}}(\mathrm{V})$ & $\mathrm{Isc}(\mathrm{mA})$ & $\mathrm{FF}(\%)$ & PCE $(\%)$ \\
\hline $\begin{array}{c}\text { Module } \\
\left(42.8 \mathrm{~cm}^{2} \text { a.a. }\right)\end{array}$ & Reverse & 16.05 & 64.13 & 70.89 & 17.05 \\
\cline { 2 - 6 } & Forward & 15.87 & 66.12 & 67.125 & 16.46 \\
\hline
\end{tabular}

Table 2. PV characteristics of the champion perovskite solar module with 14 series connected cells.

\begin{tabular}{|l|l|l|l|}
\hline Active Area & $42.8 \mathrm{~cm}^{2}$ & Voc & $16.05 \mathrm{~V}$ \\
\hline Pmax & $729.5 \mathrm{~mW}$ & Isc & $64.13 \mathrm{~mA}$ \\
\hline Vmp & $12.75 \mathrm{~V}$ & FF & $70.9 \%$ \\
\hline Imp & $57.23 \mathrm{~m}$ & PCE & $17.05 \%$ \\
\hline
\end{tabular}

a)

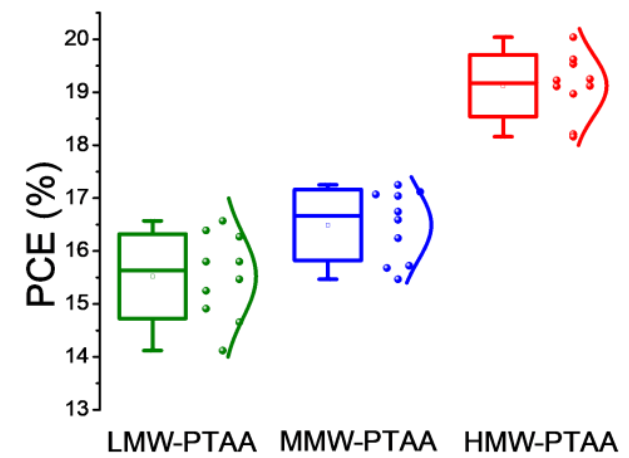

b)

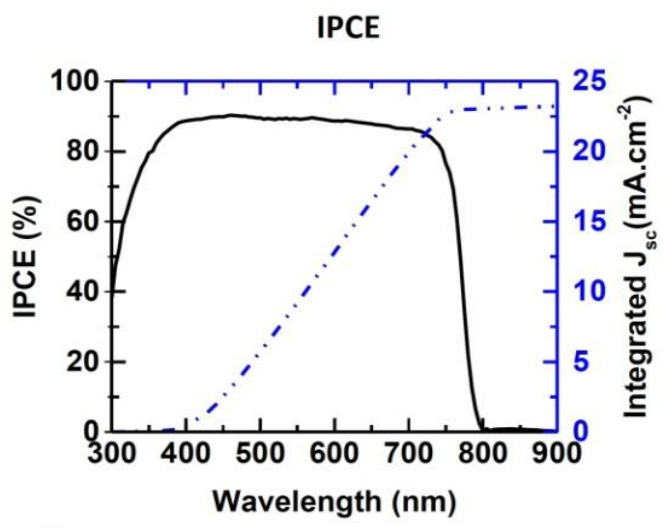


c)

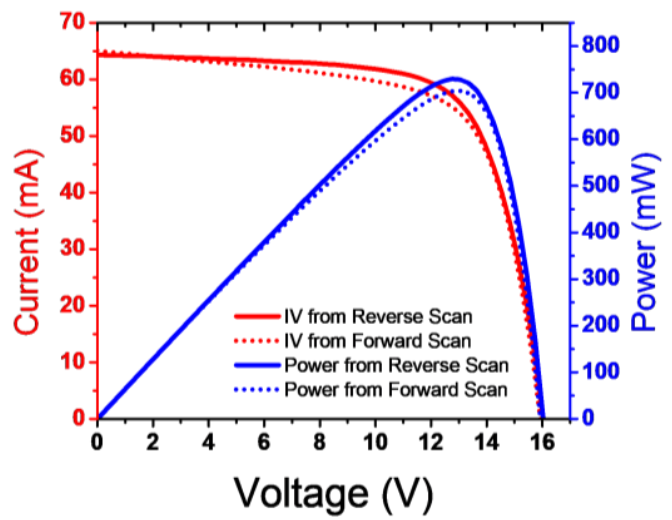

d)

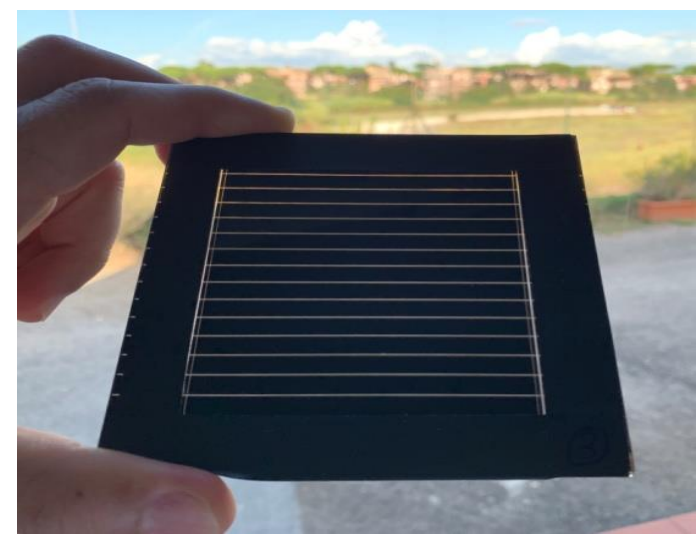

Figure 2. a) Statistical distribution of PCEs for small area PSCs made with different MWs of doped-PTAA HTL. b) Incident photon to current efficiency (IPCE) of the champion small cell. c) JV plot of the champion module with sweeping of the voltage in both forward and reverse scans. This module generates $729.5 \mathrm{~mW}$ of output power at the maximum powerpoint. d) Photograph of the fabricated module. All the PV parameters of the PSCs and module were analysed under standard 1 sun simulated illumination (AM1.5G), $\sim 65^{\circ} \mathrm{C}$ and relative humidity $(\mathrm{RH})$ around $70 \%$.

To evaluate the thermal stability of our devices and identify the impact of PTAA MW on this important aspect for PSC development, we performed an accelerated aging test of large area $\left(1.0 \mathrm{~cm}^{2}\right.$ active area) devices with the three doped-PTAA MWs, namely $10 \mathrm{kDa}$ (LMW), $37 \mathrm{kDa}$ (MMW) and $115 \mathrm{kDa}(\mathrm{HMW})$. The test was carried out at $85{ }^{\circ} \mathrm{C}$ and evidenced that the best thermal stability is achieved for the high MW doped-PTAA (Figure 3). For lower MW PTAA cells the main contribution to PCE reduction comes from Jsc and for the medium MW PTAA also from FF, Voc (see Figure S3). The PSCs containing HMW-PTAA retain more than $90 \%$ of the initial efficiency after 1080 hours thermal stress at $85^{\circ} \mathrm{C}$. Maximum Power Point Tracking (MPPT) of HMW-PTAA large area PSCs and Modules under 1 sun (AM 1.5G) continuous illumination measured in air at $70 \%$ relative humidity $(\mathrm{RH})$ are presented in Figure S4b-e. A similar thermal stress test at $85^{\circ} \mathrm{C}$ was performed with the encapsulated module and the variation of the efficiency measured as a function of stress time is reported in Figure $3 \mathrm{~b}$ and S4A. Similar to the large area cells, the module is also stable by keeping above $90 \%$ of the initial efficiency after 800 hours thermal stress at $85^{\circ} \mathrm{C}$.

On the other hand, light stability of the encapsulated large area PSC containing HMW PTAA was studied via tracking of the device against 1 sun light soaking ( $\sim 150$ hours analysis). As presented in Figure 3c, this device retains $87 \%$ of initial efficiency after 160 hours exposure against 1 sun light soaking. 
a)

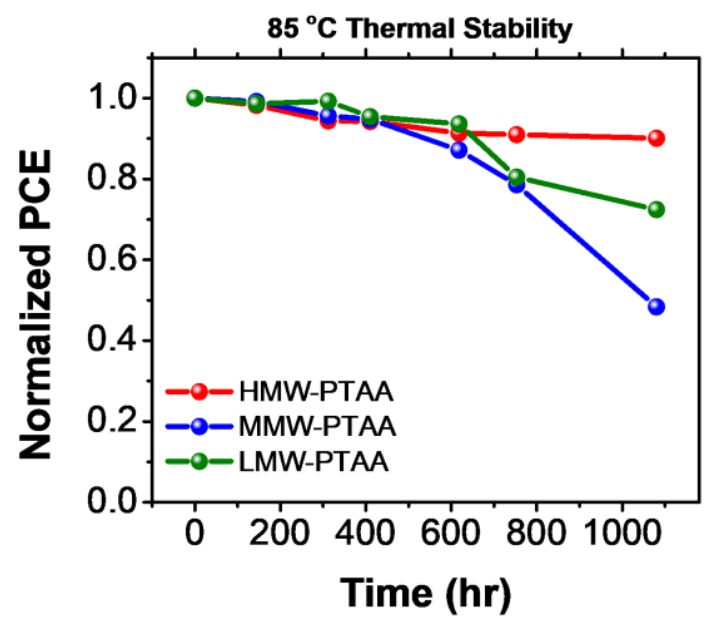

c)

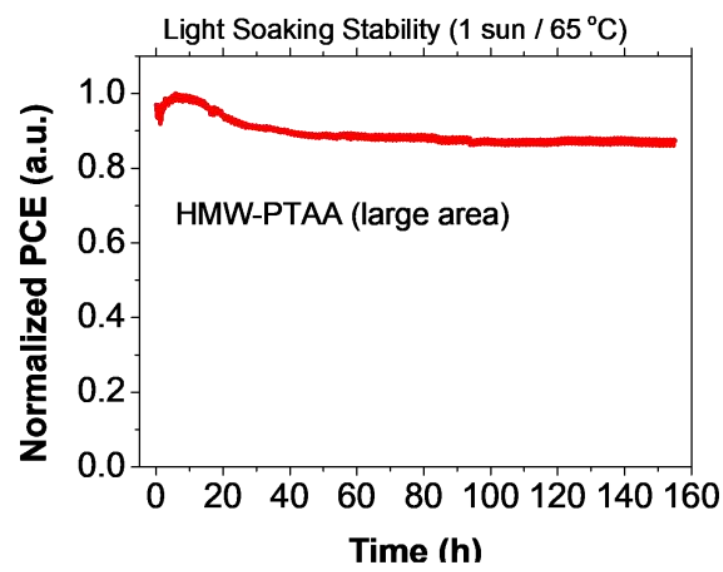

b)

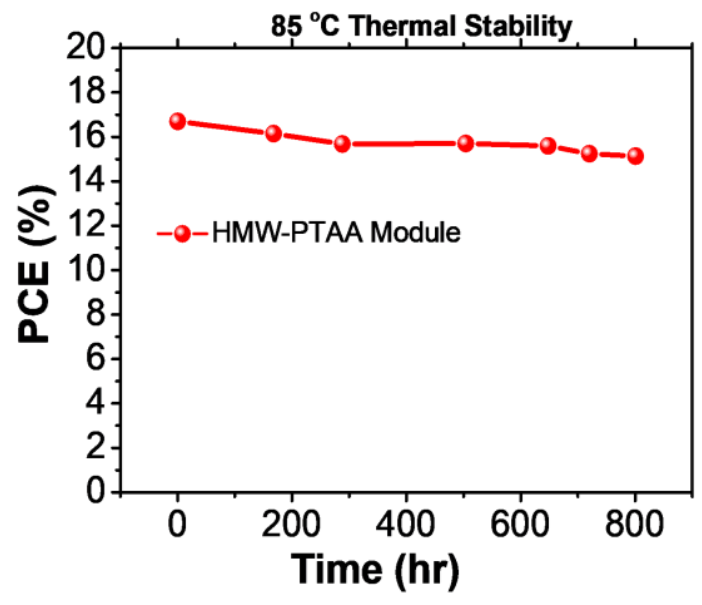

Figure 3. Thermal stability of PCE under continuous $85^{\circ} \mathrm{C}$ thermal stress (RH:70\%) for a) the large area PSCs fabricated by varying the MW of doped-PTAA HTL, b) encapsulated module fabricated with the high MW doped-PTAA. c) Light soaking test $\left(65^{\circ} \mathrm{C}\right.$ and $\left.70 \% \mathrm{RH}\right)$ of large area cell containg HMW doped-PTAA as HTM.

\section{Discussion}

\subsection{Efficiency}

In order to understand the relation between the MW of PTAA and the photovoltaic parameters we performed a series of studies intended to analyse the PTAA/Perovskite interface and the transport in the PTAA.

Electrochemical response of the perovskite interface with different MW of the doped PTAA layers was observed by potentiostatic electrochemical impedance spectroscopy (EIS) of PSCs under dark conditions and zero bias voltage. As shown in Figure 4a, the Nyquist plot (with equivalent circuit in the Figure S5) is composed of one semicircle at low frequency, with the series resistance (Rs) mainly related to the resistance of the FTO substrate.[63] This semicircle in the low-frequency range is associated with the recombination resistance (R1) at the HTL/perovskite interface.[24,43,64] The increase of the recombination resistance by increasing the MW shows that for higher MWs the interfacial recombination reduces, which justify the increase of Voc observed PSCs with high MW doped-PTAA (Figure S1b). This interfacial recombination reduction could be attributed to more delocalized polarons in the longer chains of the polymer [23], also confirmed by broadband dielectric spectroscopy results, which are later explained in Figure 5e section. 
To further assess the perovskite/HTL interface, we carried out cyclic voltammetry (CV) analyses of the PSCs with different MWs of doped PTAA device under dark conditions. The Tafel plots of the CV analysis are presented in Figure 4b. If the device is kept in dark, the intensity of the current flowing through the device has the following dependence on the applied voltage:[65]

$$
\mathrm{I}=\mathrm{I}_{01} \mathrm{e}^{\frac{\mathrm{V}-\mathrm{IR} \mathrm{S}}{2 \mathrm{kt} / \mathrm{q}}}+\mathrm{I}_{02} \mathrm{e}^{\frac{\mathrm{V}-\mathrm{IR} \mathrm{S}}{\mathrm{kt} / \mathrm{q}}}+\frac{\mathrm{V}-\mathrm{IR} \mathrm{S}}{\mathrm{R}_{\mathrm{SH}}}
$$

where $\mathrm{R}_{\mathrm{S}}$ and $\mathrm{R}_{\mathrm{SH}}$ are the series and shunt resistance and $\mathrm{I}_{01}$ and $\mathrm{I}_{02}$ are diode saturation currents of the device, respectively. Considering Equation 1 and the experimental results, we identify four bias regions in the IV characteristics: 1) $\mathrm{V}<\mathrm{V}_{1}$, dark current will be related to the shunt resistance; 2) $\mathrm{V}_{1}<\mathrm{V}<\mathrm{V}_{2}$, the dominant term is the first exponential of Equation 1 which is related to the recombination in the depletion zone; 3) $\mathrm{V}_{2}<\mathrm{V}<\mathrm{V}_{3}$, the dominant term is the second exponential of Equation 1 that is related to trap assisted and radiative recombination; 4) $V>V_{3}$ dark current is limited by the series resistance and will saturate. In our PSCs, by increasing the PTAA MW, recombination in the depletion zone occurs at lower voltage ranges. This has a positive effect for high MW doped-PTAA at the perovskite/HTL interface, reducing the direct interfacial non-radiative recombination and enhancing the rate of hole extraction, which is the third term on the right-hand side of Equation 1. At $\mathrm{V}_{2}$, when the bias voltage exceeded the kink point corresponding to trap-filled limit voltage $\left(\mathrm{V}_{\mathrm{TFL}}\right),[66,67]$ the current increased rapidly, showing that the trap states were completely filled. Extracted the main fitting parameters of the curves including trap-filled limit voltage $\left(\mathrm{V}_{\mathrm{TFL}}\right)$, reverse saturation current density $\left(\mathrm{J}_{0}\right)$, first saturation current density $\left(\mathrm{J}_{01}\right)$, second saturation current density $\left(\mathrm{J}_{02}\right)$ and shunt resistance $\left(\mathrm{R}_{\mathrm{SH}}\right)$ are presented in Table S4. The dark JV results are in line with EIS, exhibiting that the photovoltaic enhancement by MW tuning of doped-PTAA occurs via a considerable decrease in interfacial charge recombination and increasing polaron delocalization.

Transient Photocurrent (TPC) and Transient Photovoltage (TPV) analysis have also been investigated for PSCs with the different MW of doped PTAA. The extracted charge versus Jsc dependence from TPC $[68,69]$ is plotted in Figure 4c. The results showing a marked improvement of hole extraction by tuning the MW from low to high. In addition, the recombination time, evaluated from TPV[68] (Figure 4d), shows longer recombination times by increasing MW. Considering that the combination of high carrier mobility together with high diffusion length of PSCs limits charge recombination at the interfaces between perovskite layer and HTL, MW tuning to higher values seems to reduce the number of recombination centers via affecting of the delocalized polarons on PSK/PTAA interface, as also confirmed by EIS and dark JV results. The improved charge extraction is also clear from Figure $4 \mathrm{c}$ in which the sample with the high MW shows the highest extracted charge at different light intensities. The linear trend also shows that there is no evident trapping phenomenon even at low light intensities, nor any saturation of the extracted charge at high intensities, proving the high quality of contact formed between the perovskite layer and the HTL.[70,71] 
a)

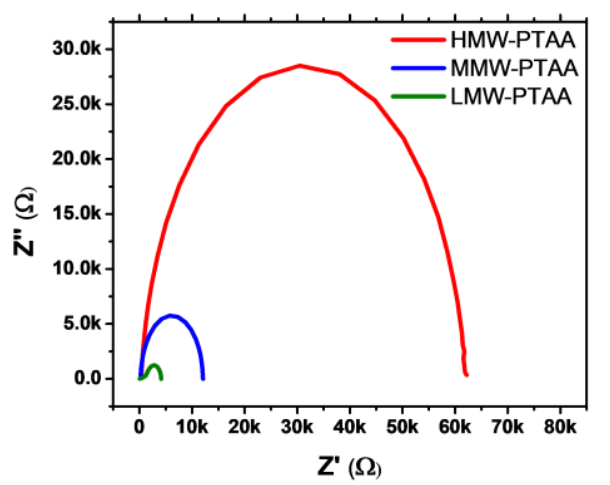

c)

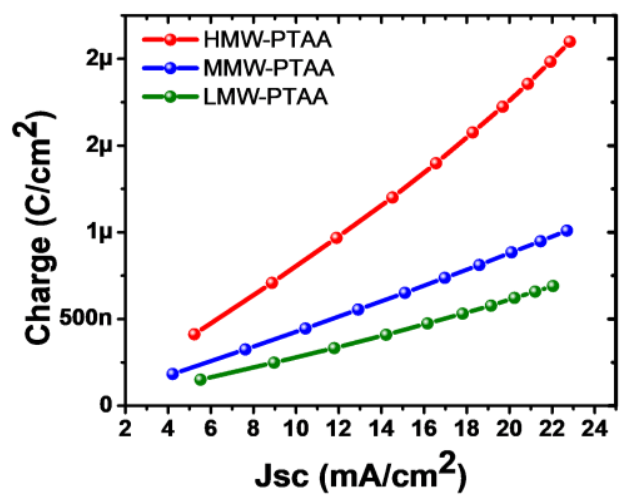

b)

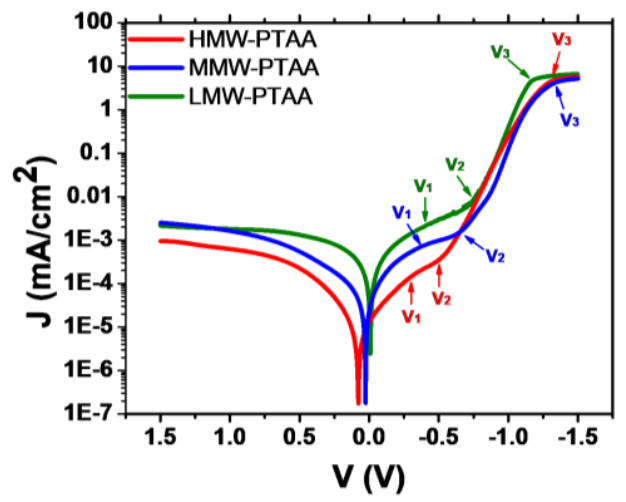

d)

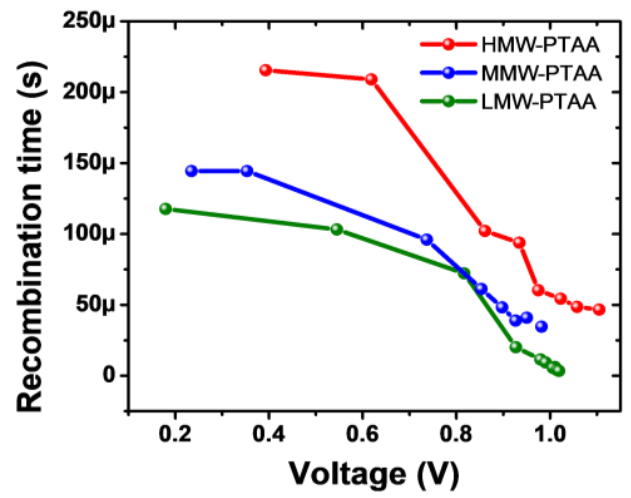

Figure 4. a) Nyquist plot of EIS results for PSCs fabricated with different MWs of dopedPTAA as HTM under dark conditions and zero bias potential. b) Tafel plots of devices with different MWs of PTAA evaluated from cyclic voltametery analysis (dark JV). The devices keep in dark conditions and the $\mathrm{CV}$ performed in the range of -1.5 to $1.5 \mathrm{~V}$ with a voltage sweep rate of $5 \mathrm{mV} / \mathrm{s}$. c) Charge extraction curves of the PSCs obtained from transient photocurrent fall/rise analysis. d) Recombination time versus voltage, evaluated from transient photovoltage decay analysis of the PSCs.

The quality of interface between perovskite and PTAA with various molecular weight were also investigated via optoelectronic characterizations including Time Resolved Photoluminescence (TRPL) as well as photoluminescence (PL). In Figure 5a,b, we show TRPL decays and initial PL $(\mathrm{t}=0)$ for the perovskite when interfaced with different MW of doped-PTAA. It is notable that in TRPL and initial PL measurements, where a pulsed laser is used, the quenching of the initial PL value directly correlates to the charge extraction efficiency because of the lack of build-up charges in the pulsed measurement.[72][73] We found that the fastest hole extraction occurs in the perovskite interfaced with high MW doped-PTAA that is consistent with higher average short circuit current and subsequently higher device performance of this configuration. Notably, the photoluminescent decay of perovskite film is comparable with the perovskites interfaced with PTAA particularly for Low and Medium molecular weight samples showing that the photoluminescence quantum yield that is directly proportional to the area below the TRPL decay translating to the formation of high quality interfaces between perovskite and PTAA.

To provide additional insight into sub-bandgap/surface states and energetic disorder at the interface between PTAA and perovskite, we performed photothermal deflection optical absorption spectroscopy (PDS)[74] of the PTAA and the perovskite with PTAA, as reported in Figure 5c,d. It is notable that changing the MW does not affect the absorption characteristic of PTAA (Figure 5c). However, the PDS spectra of perovskite films capped with different MWs of PTAA shows 
more effective doping in the case of the highest MW that is consistent with conductivity measurement (Figure 5d). In fact, the below bandgap feature of a broad peak at low energies in the absorption spectra of the perovskite film that is interfaced with HTL is previously showed to be correlated to oxidation of the molecular semiconductor.[75] This, in turn, could increase the extraction of holes as demonstrated for Spiro-OMeTAD.[76][73]

Broadband dielectric spectroscopy was used to measure the AC conductivity variation of PTAA for fresh and temperature stressed sample. The AC conductivity at constant temperature can be represented as:

$$
\sigma_{a c}(\omega)=\sigma_{d c}+A(\omega)^{s}
$$

where $\sigma_{d c}$ is the limit of $\sigma_{a c}$ as $\omega \rightarrow 0$. A and s are fitting parameters depend on doping and temperature. Equation 2 generally called universal ac conductivity law since it can describe the behaviour of wide variety of disordered materials.[77] Figure $\mathbf{S 6}$ displays the AC conductivity of the pristine PTAA and related doped samples. To unveil the effect of temperature and doping on conductivity of the samples DC conductivity $\left(\sigma_{a c}\right)$ values are extracted from the data and reported in Figure 5e. The conductivity of doped PTAA samples increases sharply by increasing the MW while does not vary for undoped PTAA. This behaviour could be explained by the combined effect of doping and better molecule orientation, which enhances the charge transfer from one chain to another.[78] Furthermore, the conductivity plateau shifts to higher frequencies with increasing the MW in doped PTAA, which demonstrates widening of conductivity relaxation region.[79]

By increasing the MW, the polaron become more delocalized resulting in an increase of the conductivity as was shown for P3HT.[23] In our case, this is only true when the PTAA is doped, while in undoped sample the conductivity is independent on the MW. Dopant molecules make a partial oxidation on the polymer chain and this partial oxidation can affect the polarity of surrounding chains impacting on the polaron formation and delocalization.[80] As show in Figure $5 \mathrm{~d}$, this oxidation is larger in high MW PTAA when interfaced with perovskite. Indeed, the mixture of three dopants namely, Bis(trifluoromethane) sulfonimidelithium salt (Li-TFSI), 4-tertButylpyridine (TBP) and tris(2-(1H-pyrazol-1-yl)-4-tert-butylpyridine) cobalt(III) tri[bis(trifluoromethane)sulfonimide] (FK209-Co(III)-TFSI), with optimized ratio (see Figure S7) lead to more delocalization of the polarons across the polymeric chains and enhance charge mobility. Accordingly, formation of arranged delocalized polarons and subsequent fast charge mobility would be boosted by increasing the MW.

a)

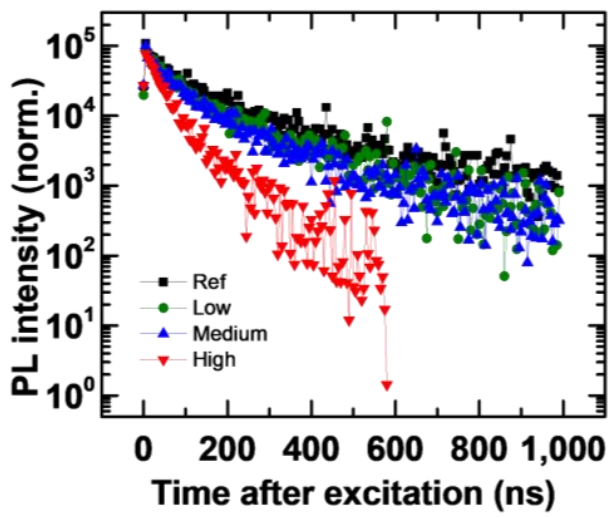

b)

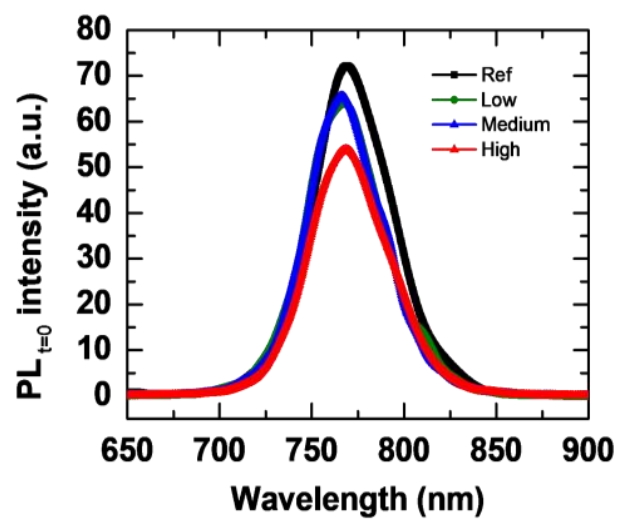


c)

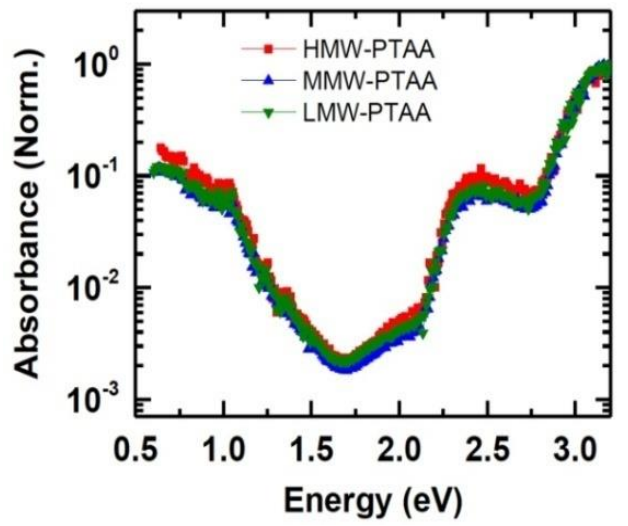

e)

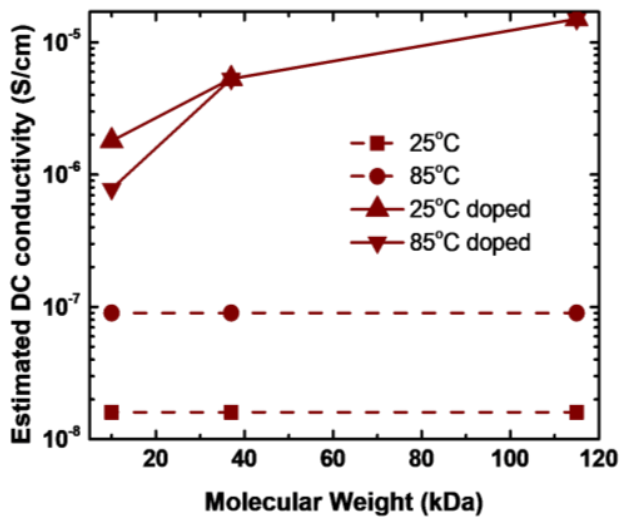

d)

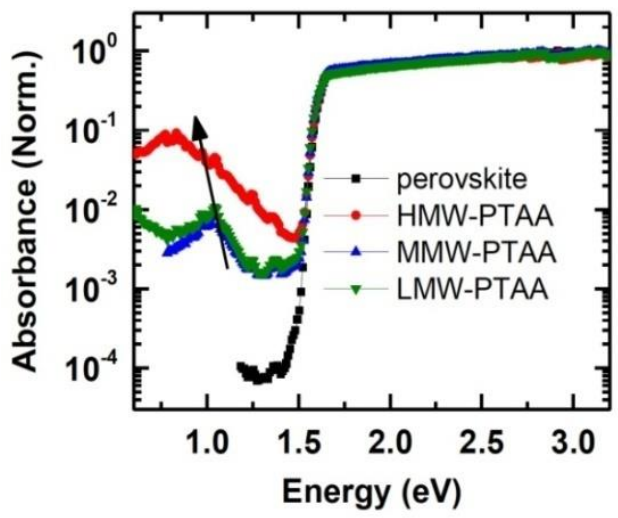

Figure 5. a) and b) time-resolved PL (TRPL) decays and initial PL $(t=0)$ for the perovskite film (Ref) and the perovskite film when interfaced with different MW of PTAA. c) and d) photothermal deflection optical absorption spectroscopy (PDS) of PTAA and Perovskite/PTAA; e) DC conductivity estimated from dielectric spectroscopy data $(\omega \rightarrow 0)$ for doped and undoped PTAA with different $\mathrm{MW}$ in a Schottky diode structure at room temperature $\left(25^{\circ} \mathrm{C}\right)$ and thermal stress $\left(85^{\circ} \mathrm{C}\right)$.

Based on the experimental investigations presented above we can assess that by increasing the MW of PTAA we increase both the charge transfer at the Perovskite/PTAA interface and the PTAA conductivity. To quantify the relative impact on the cell efficiency of these two phenomena we produce a series of PSCs by using undoped low and high MW PTAA (Figure S8). By comparing the efficiencies PSC with doped and undoped PTAA we see that the dependence on the PTAA's MW is similar on both cases (even with similar relative variations between low and high MW), while the overall efficiency magnitude depends directly on the doping of PTAA. Thus, while the doping impact on the efficiency of the PSC irrespectively on the PTAA MW, the dependence of PSC efficiency on PTAA's MW is mainly related to the improved charge transfer efficiency.

\subsection{Thermal stability}

To investigate the thermal stability of the doped samples AC conductivity has been measured after keeping the samples at $85^{\circ} \mathrm{C}$ for one hour (Figure 5e). For undoped sample conductivity increase after thermal stress while MW has no effect on conductivity of these samples. On the opposite, for doped samples temperature has not an important role on conductivity, while, as discussed, the impact of MW is dominant.

To clarify the impact of thermal stress on the local morphology and chemical composition of PSCs with different doped-PTAA MWs, we performed cross-sectional imaging and energydispersive X-ray spectroscopy in a scanning transmission electron microscope (STEM-EDX). 
Figure 6a shows cross-sectional STEM high-angle annular dark-field (HAADF) images of lamellae extracted from fresh and stressed large area PSCs with medium and high PTAA MW, where we can see a void (circled in red) at the top surface of stressed perovskite layer with medium MW (MMW) PTAA. As apparent from Figure 6a, each solar cell stack is composed of, from bottom to top, fluorinated-tin oxide/compact- $\mathrm{TiO}_{2} /$ mesoporous- $\mathrm{TiO}_{2} /$ perovskite/PTAA/Au. STEM-EDX data were acquired from the areas shown in Figure 6a and analyzed with nonnegative matrix factorization (NMF) to decompose the dataset into components corresponding to specific chemical phases[81]. Three NMF components were selected and shown in Figure 6bd, with their spectra plotted in Figure 6e. In the images and chemical phase maps shown in Figure $6 \mathrm{a}-\mathrm{d}$, we see various non-perovskite phases occupying a significant volume fraction of the perovskite layer. The chemical compositions of these phases vary with respect to the bulk perovskite, from being richer in $\mathrm{Pb}$ and I (brighter areas in Figure 6b), Cs and I (Figure 6c), or Pb and $\mathrm{Br}$ (Figure $6 \mathrm{~d}$ ). These non-perovskite phases can either be unreacted precursors or products of thermal decomposition of perovskite, or perhaps both. Given that they are also present in the MMW fresh sample (and to a much lesser extent in the HMW fresh sample), at least some of them must be unreacted precursors instead of decomposition products. Therefore, we cannot definitively attribute the cause of post-stress performance decline to these non-perovskite phases. However, we also note that in both fresh samples, the concentration of bromine peaked at the perovskite-PTAA interface (Figure 6d). Heating partially pushed the bromide anions back to the bulk of the perovskite layer, but to a greater extent in the MMW sample compared to HMW sample. This loss of bromine-rich layer is a possible cause of PCE reduction in the stressed samples. The bromine-rich perovskite blocks electron transfer into PTAA and reduces interfacial charge recombination due to its higher conduction band minimum energy level, thereby increasing Voc and FF in a manner similar to that proposed by Cho et al[82]. We note that this proposed mechanism is in excellent agreement with how Voc and FF evolve during the thermal stability test (Figure S3a,c). The reason why MW of PTAA has an impact on bromine accumulation after thermal stress could be related to the structural modification of perovskite interface induced by the PTAA which varies with the MW and some on us shown recently[83], and in particular by increasing the PTAA MW the content of Br based products increases and shown by GIWAX measurements of Ref.[83]. In particular, Yaghoobi Nia et al. clearly evidenced that increasing of the doped PTAA MW led to formation of a cesium lead bromide phase in the perovskite/HTM interface. In particular, the irregular FF reinforcement of the LMW samples during the thermal stress could be attributed to positive rearrangement of the polymeric chains toward enhances $\pi-\pi$ stacking[84] and/or thermally induced reversible polaron/bipolaron transition[85] which led to lower Br-rich loss in the PSK/HTM interface compare to MMW samples.

We should also consider that the robustness of high MW doped-PTAA could be explained considering that the degradation of polymers starts at the sides of the chain and in materials with a higher number of shorter chains (low MW) there will be a larger density of decomposition sites.[86] Here, we should point out that the difference between MWs is not related to the decomposition temperatures which is similar $\left(490^{\circ} \mathrm{C}\right)$ for all the $\mathrm{MW}$ and it is well above operational conditions (Figure S9). The increased stability of HTM polymers for increasing MWs has been also reported by Yang and co-workers.[87] In particular, Lee et al. are reported the effect of PTAA MW tuning (from low to medium values) on the stability of the flexible planar PSCs against moisture and mechanical stresses where higher MWs leads to more robust films.[26] 


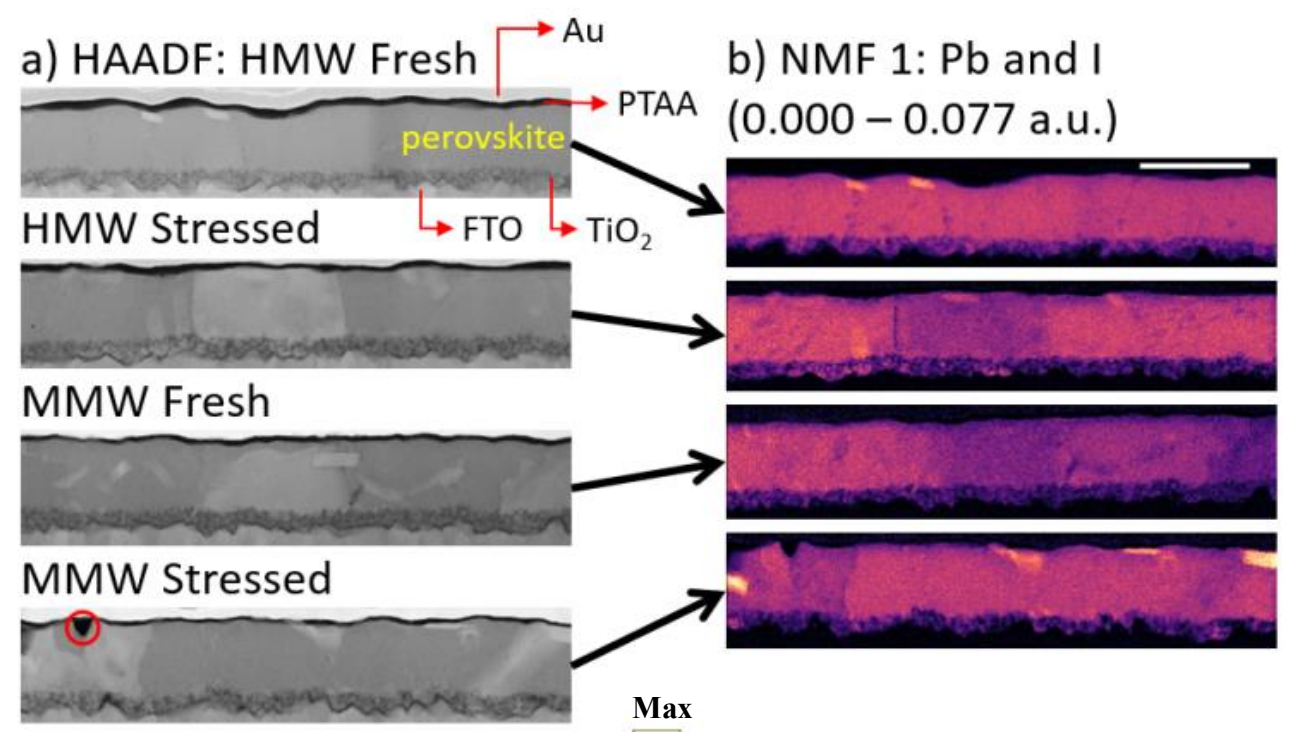

c) NMF 2: Cs and I (0.000 - 0.145 a.u.)

d) NMF 3: $\mathrm{Pb}$ and $\mathrm{Br}$
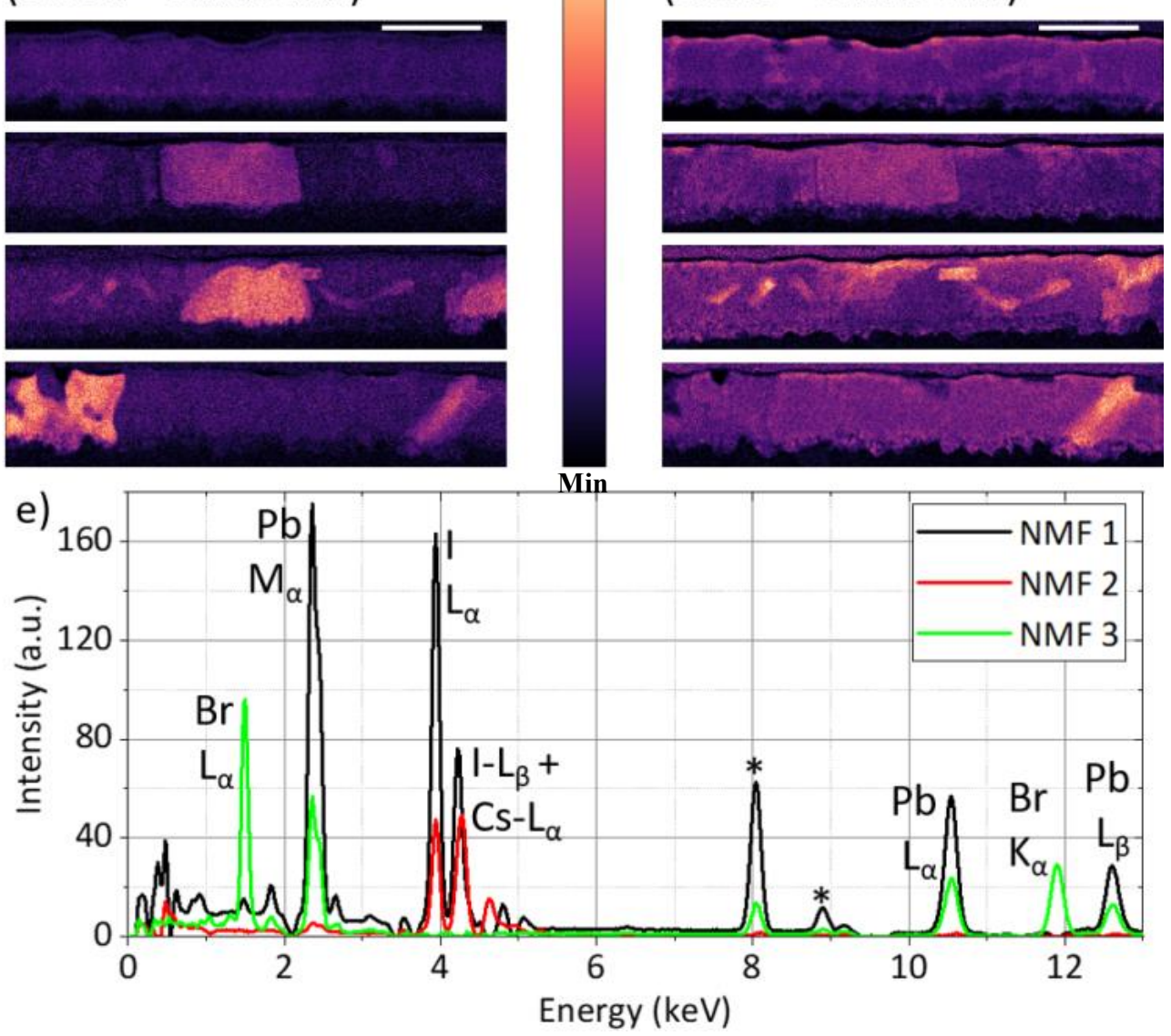

Figure 6. a) Cross-sectional STEM-HAADF images of lamellae cut from large area PSCs with medium and high MW doped-PTAA, before and after 1000 hours thermal stress. The PSC's layers are labeled on the top image. b-d) NMF phase decomposition of EDX data for the areas shown in (a), showing the (b) primary perovskite and $\mathrm{Pb}$,I-rich phase, (c) Cs,I-rich phase, and (d) $\mathrm{Pb}, \mathrm{Br}$-rich phase. The spectrum for each phase is plotted in (e). Scale bars represent 1 $\mu \mathrm{m}$ and are applicable to all NMF maps and HAADF images. The colour scale applies for panels (b-d), where the minimum and maximum values for each set of NMF maps are as stated in the respective panel. In each panel, brighter colours indicate higher signal intensities for the phase of interest." 


\section{Conclusion}

We studied the influence of molecular weight and polaron arrangement of doped PTAA on the performance and stability of n-i-p perovskite solar cells. Considering the experimental investigation presented above, we can clearly relate the performances of PSC to two main phenomena. The first one is the reduction of non-radiative interfacial recombination when the MW of PTAA is increased. As the MW of doped-PTAA increases, the charge extraction from the perovskite active layer is more effective, and carriers have a lower chance of recombining non-radiatively. The explanation for this come from the fact that, similarly to what happens for P3HT,[23] as the MW of doped-PTAA increases, the polarons resulting from the interaction between the charges and the polymer will be more delocalized, as longer chain molecules will exhibit a lower degree of vibrations.[88,89] The second phenomena is related to the increase of PTAA DC conductivity by increasing the MW of PTAA. This happens, however, only for doped PTAA while pristine PTAA does not show this behaviour. Here, a higher degree of delocalization of charge along the chain of the doped PTAA molecules will result in an improved mobility.[90] These two phenomena, however, influence the PSC efficiency differently: while the doping of PTAA influences the overall efficiency, the main contribution to the dependence of PCE on PTAA's MW arises from the charge transfer at the perovskite/PTAA interface.

An additional positive side-effect of employing a higher molecular weight doped PTAA is the improved thermal stability of the PSCs, because of the stronger resilience of longer chains to the thermal stress and the improved passivation of the perovskite/HTL interface due to accumulation of bromine, as emerging from the TEM analysis. The increase of delocalized polarons in the HMW PTAA layer can also positively affect the underlying perovskite lattice and improve the overall stability of the device. In particular, this interesting phenomenon might be attributed to the strong electrostatic attraction of the ionic moieties of the dopants which are stabilized in the perovskite/HTM interface [91] and demonstration of a dynamic disorder in the perovskite lattice which leads to localization of charge carriers into states known as large polarons, which reduces their mobility but greatly extends their lifetime.[92]

The use of high MW doped-PTAA permits to increase the efficiency of our small area cells (more than 20\%), and to demonstrate an over 17\% efficient perovskite module (active area of $42.8 \mathrm{~cm}^{2}$ ), which is among the best in this area size. Both Large area and modules have an extrapolated $\mathrm{T} 80$ of more than 2500 hours under stress at $85{ }^{\circ} \mathrm{C}$ in ambient. In addition, large area PSCs containing HMW PTAA show around 800 hours extrapolated lifetime against 1 sun light soaking test.

These results demonstrate that high MW doped-PTAA is a viable replacement for SpiroOMeTAD in conventional n-i-p PSCs, combining high efficiency with stability. All this will be crucial for industrial exploitation of this very promising PV technology.

\section{Experimental section}

Device fabrication: Etching of the FTO/glass substrates (Pilkington, $15 \Omega / \square, 25 \mathrm{~mm} \times 25 \mathrm{~mm}$ ) was performed using a raster scanning laser $\left(\mathrm{Nd}: \mathrm{YVO}_{4}\right.$ pulsed at $30 \mathrm{kHz}$ average output power $\left.\mathrm{P}=10 \mathrm{~W}\right)$. For the small area devices the FTO substrates is LASER patterned to contain 4 separate pixels, while for the large-area devices the substrate contain only one cell.

A stepwise ultrasonic bath cleaning process was applied to the patterned substrates by using detergent aqueous solution, de-ionized water, and 2-propanol, respectively and 3 minutes for 
each step. A $50 \mathrm{~nm}$ of compact $\mathrm{TiO}_{2}\left(\mathrm{c}-\mathrm{TiO}_{2}\right)$ layer was deposited onto the patterned FTO by spray pyrolysis deposition at $450{ }^{\circ} \mathrm{C}$ and 15 spray cycles, using a previously reported procedure.[24] Nanocrystalline mesoporous $\mathrm{TiO}_{2}$ was deposited on the $\mathrm{c}-\mathrm{TiO}_{2}$ layer by using a diluted commercial paste (30-NRD paste, Dyesol diluted in ethanol 1:6 w/w) and spin coating with $5000 \mathrm{rpm}$ for 20 second and sintered using an stepwise annealing elevation ramp from room temperature to $480{ }^{\circ} \mathrm{C}$.[63] Subsequently, a Li-TFSI treatment process was done via static spin coating of Bis(trifluoromethane)sulfonimide lithium salt in acetonitrile $(34.8 \mathrm{mM})$ solution on the $\mathrm{mp}-\mathrm{TiO}_{2}$ layer. Indeed, $200 \mu \mathrm{l}$ of this solution was loaded on the substrate and was spin coated after 7 seconds at 3000 r.p.m for 10 seconds, following sintering program same as mp$\mathrm{TiO}_{2}$ and subsequently cooled down to $150{ }^{\circ} \mathrm{C}$. The hot substrates were transferred immediately to the glove box. The process for preparation of the perovskite solution and deposition on $\mathrm{mp}$ $\mathrm{TiO}_{2}$ layer was followed as previously reported procedure.[63] Device structure is shown in

\section{Figure S10.}

Doping Optimization for the PTAA solution: In our recent work on P3HT as HSL of perovskite solar cells we applied a doping strategy for markedly enhancement the performance of the devices and solar modules.[63] In particular, doped P3HT shows an interesting candidate for upscaling from small area devices to large area perovskite solar modules. Mixture of three dopants including Li-TFSI, TBP, and FK209-Co(III)-TFSI were used as additive into the PTAA solution. Three types of dopant mixtures have been prepared as following. 1) Mixed of Li-TFSI and TBP (21:79 mol\%); 2) Li-TFSI, TPB and FK209 (20:78:2 mol\%); 3) Li-TFSI, TPB and FK209 $(19: 77: 4 \mathrm{~mol} \%)$ and the ratio of 20:78:2 was selected as the optimized mixture for all the PTAA solutions, (see Figure S7).

HTM and back contact deposition: Different concentration of each MW PTAA (LMW: 2 mM, MMW: $0.54 \mathrm{mM}$ and HMW: $0.173 \mathrm{mM}$ ) solution in chlorobenzene were doped with LiTFSI/ TBP/FK209 Co(III)-TFSI (20:78:2 mol\%) and aged for 1 hours. The HTM solutions were deposited on the perovskite layer via spin coating at 6000 r.p.m for 45 second with acceleration rate 6000 (static coating for LMW and MMW and dynamic coating for HMW) in order to reach 50-60 nm thickness for all HTM samples. All MWs of PTAA have been doped in the same way. Finally $100 \mathrm{~nm}$ gold was deposited on the substrates via a vacuum metal evaporator.

Module Fabrication: In order to produce Perovskite Solar Modules, we adopted the P1-P2-P3 patterning procedure. $[93,94]$ The $\mathrm{P} 1$ process was performed by means of a $\mathrm{Nd}: \mathrm{YVO}_{4} \mathrm{~ns}$ laser $(\lambda$ $=355 \mathrm{~nm}$, Fluence $=10.2 \mathrm{~J} / \mathrm{cm}^{2}$ ) in order to patterning and insulate the FTO cells. The patterned FTO substrates (Pilkington, $15 \Omega \mathrm{cm}^{-1}, 100 \mathrm{~mm} \times 100 \mathrm{~mm}$ ) were cleaned same as small and large area devices. Afterwards, the substrates were kept on a hot plate, reaching $460{ }^{\circ} \mathrm{C}$ in $40 \mathrm{~min}$ and the solution for spray (the same for small area) was deposited by spray pyrolysis to reach $50 \mathrm{~nm}$ ${\mathrm{c}-\mathrm{TiO}_{2}}_{2}$ thicknesses. Owing to deposition of the mesoporous layer, 30-NRD paste (Dyesol) was diluted with ethanol (1:6 w/w ratio) and deposited for 20 second at 4000 r.p.m. with a ramp of 2000 r.p.m. The substrates were annealed using same stepwise program mentioned for small area devices. Afterward, Li-salt treatment was performed on the mesoporous layer by loading/deposition of Bis(trifluoromethane)sulfonimide lithium salt in acetonitrile $(34.8 \mathrm{mM})$ solution via 7 second loading time and subsequently spin coating at 3000 r.p.m following sintering program same as $\mathrm{mp}-\mathrm{TiO}_{2}$. In the next step for deposition of the perovskite layer we used a stepwise spin coating procedure, firstly perovskite solution was deposited on the substrate and spin coating at $1000 \mathrm{rpm}$ for $10 \mathrm{~s}$ with $200 \mathrm{rpm} / \mathrm{s}$ acceleration, and then the second step at 4000 $\mathrm{rpm}$ for $20 \mathrm{~s}$ with $2000 \mathrm{rpm} / \mathrm{s}$ ramp, finally in the last second step, chlorobenzene was dynamic dispense spin casted on the substrate to precipitate the perovskite intermediate. The substrates 
then were transferred on a hot plate for sintering at $100{ }^{\circ} \mathrm{C}$ for 1 hour in order to complete crystal growth. PTAA solution was dynamic dispense spin coated on the perovskite layer through a 30 second spin coating at 4000 r.p.m. After the deposition of Perovskite and PTAA layers, the P2 patterning process was applied to remove the ESL-Perovskite-HSL stack from the underneath the FTO, owing to realize a vertical contacts between the latter and the subsequently deposited electrode. The P2 step was applied by means of a Nd:YVO $\mathrm{YV}_{4}$ laser $(\lambda=355 \mathrm{~nm}$, Fluence $=155 \mathrm{~mJ} / \mathrm{cm}^{2}$ ). Finally, $100 \mathrm{~nm}$ gold was deposited as back contact electrode via vacuum evaporation, and a P3 laser patterning step was realized to insulate the counter-electrodes of the single cells, employing a Nd: $\mathrm{YVO}_{4} \mathrm{~ns}$ laser $\left(\lambda=355 \mathrm{~nm}\right.$, Fluence $\left.=59 \mathrm{~mJ} / \mathrm{cm}^{2}\right)$.

Schottky diode Fabrication: gold bottom electrodes were deposited on a clean glass substrate; afterward, $5 \mathrm{wt} \%$ solution drop casted on a glass substrate. After drying the film top electrodes were deposited, the device area was $0.0016 \mathrm{~cm}^{2}$.

Device measurement and instruments: Photovoltaic performance of the devices and modules was analyzed through measurement of masked devices under a solar simulator (ABET Sun 2000, class A) at AM1.5G and $100 \mathrm{~mW} \mathrm{~cm}{ }^{-2}$ illumination conditions which was calibrated with a certified reference Si Cell (RERA Solutions RR-1002). The incident power was checked with a Skye SKS 1110 sensor. Dark JV measurement from fabricated PSCs was performed using cyclic Voltammetery module of AUTOLAB potentiostate instrument. Electrochemical impedance spectroscopy was done via AUTOLAB. TPV, TPC was measured with a commercial apparatus (Arkeo, Cicci Research s.r.l.) based on a high speed Waveform Generator that drives a high speed LED (5000 Kelvin).

Encapsulation Procedure for Large area cells and Module PSCs: For the encapsulation of device we used a very simple and cheap method that avoids the use of temperature and pressure on the device. The device's surface was carefully covered with the microscope slides (same size as device), then fully sealed with the Thread seal tape (also known as Teflone PTFE tape) which is a polytetrafluoroethylene (PTFE) film tape (please see Figure S11). PTFE is completely stable up to $+260^{\circ} \mathrm{C}$ and decomposition is above $400^{\circ} \mathrm{C}$. PTFE did not show any reaction with the layers in the PSCs since PTFE is chemically inert. Encapsulated device is shown in Figure S11. In our sealing process we did not use any glue, thus it is possible to easily open the sealing at any time.

Scanning transmission electron microscope characterization: Cross-sectional sample lamellae were cut and thinned to electron transparency $(\sim 200 \mathrm{~nm})$ with a FEI Helios NanolabDualbeam FIB/SEM following a standard protocol.[95] The lamellae were then directly transferred into a FEI Osiris TEM operated at $200 \mathrm{kV}$, minimising air exposure to 2 minutes. To minimize beam damage, STEM-EDX SIs were acquired using a defocused beam $(\Delta \mathrm{f}=-1 \mu \mathrm{m})$, a beam current of $\sim 250 \mathrm{pA}$, dwell time of $50 \mathrm{~ms} / \mathrm{pixel}$, and spatial sampling of $10 \mathrm{~nm} /$ pixel. STEM-EDX SIs were analysed in HyperSpy[96] using anon-negative matrix factorization algorithm for decomposition into distinct components.[81]

Photothermal Deflection Spectroscopy: PDS is a scatter- free surface sensitive absorption measurement. Perovskite films were excited with a modulated monochromated light beam perpendicular to the plane of the sample. A combination of a Light Support MKII $100 \mathrm{~W}$ xenon arc source and a CVI DK240 monochromator was used to produce a modulated monochromated light beam. The laser probe beam was produced with Qioptiq 670- nm fiber- coupled diode laser and directed parallel to the perovskite film surface. A white- light LED source with an intensity of $100 \mathrm{~mW} \mathrm{~cm}{ }^{-2}$ was used to light- soak the perovskite films. 
Photoluminescence Characterization: Photoluminescence spectra were measured using an integrating sphere and a $532 \mathrm{~nm} \mathrm{CW}$ laser at an illumination intensity of $\approx 60 \mathrm{~mW} \mathrm{~cm}^{-2}$.

Time- Resolved Photoluminescence Measurements: Time- resolved PL spectra were recorded using a gated intensified CCD camera (AndoriStar DH740 CCI- 010) connected to a calibrated grating spectrometer (Andor SR303i). A Ti:sapphire optical amplifier $(1 \mathrm{kHz}$ repetition rate, 90 fs pulse width) was used to generate narrow bandwidth photoexcitation $(10 \mathrm{~nm}$ full- width at half maximum (FWHM)) with a wavelength of $550 \mathrm{~nm}$, via a custom- built non-collinear optical parametric amplifier. Light soaking of perovskite films was performed during the measurement using a laser source with a wavelength of $532 \mathrm{~nm}$ and an intensity of $60 \mathrm{~mW} \mathrm{~cm}$. The emitted steady- state photoluminescence was collected via an optical fiber coupled to an Ocean Optics Maya2000 Pro spectrometer.

External Quantum Efficiency (EQE): The EQE spectra were recorded as a function of wavelength under a constant white light bias of approximately $5 \mathrm{~mW} . \mathrm{cm}^{-2}$ supplied by an array of white light emitting diodes. The excitation beam coming from a $300 \mathrm{~W}$ xenon lamp (ILCTechnology) was focused through a Gemini-180 double monochromator (JobinYvon Ltd) and chopped at approximately $2 \mathrm{~Hz}$. The signal was recorded using a Model SR830 DSP Lock-In Amplifier (Stanford Research Systems). All measurements were conducted using a nonreflective metal aperture of $0.105 \mathrm{~cm}^{2}$ to define the active area of the device and avoid light scattering through the sides.

Broadband dielectric spectroscopy was measured using Novocontrol equipped with Linkam LTS420 heating-cooling hot-stage in the frequency range of $10^{\circ}-10^{-6}$ at $25^{\circ} \mathrm{C}$ and $85^{\circ} \mathrm{C}$.

TGA of different $M W$ of PTAA: Themogravimetric analyses were carried out using Mettler Toledo TGA/DSC3+ from 20 to $700{ }^{\circ} \mathrm{C}$ at $10^{\circ} \mathrm{C} / \mathrm{min}$ under $\mathrm{N}_{2}$ atmosphere.

Materials: $\mathrm{PbI}_{2}$ and $\mathrm{PbBr}_{2}$ is from TCI company, FAI, MABr from Sigma Aldrich, PTAA with different MWs is from Solaris Chem Inc. The poly dispersity index (PDI) of PTAA with MW of $10 \mathrm{kDa}, 37 \mathrm{kDa}$ and $115 \mathrm{kDa}$ PTAA MWs is $1.4,1.7$ and 3.1, respectively as reported by the company. The glass transition temperature (Tg) values of PTAA with the different MWs have been reported by Lee et al.[26]), $\mathrm{TiO}_{2} 30 \mathrm{NRD}$ from dyesol company, CsI powder from abcr GMBH company, Li-TFSI form sigama Aldrich, FK209 Co(III)-TFSI from sigma Aldrich.

\section{ASSOCIATED CONTENT}

\section{Supporting Information}

The Supporting Information is available free of charge on the Publications website. The following concepts will be presented in supporting information file:

- Statistical photovoltaic parameters of the small area PSCs;

- Photovoltaic characteristics of the most efficient devices;

- Statistical distribution of PV parameters of perovskite solar module;

- Photovoltaic characteristics of the most efficient Module;

- Thermal stability results (PV parameters) of the large area perovskite solar cells;

- Thermal stability and MPP tracking;

- EIS equivalent fitting circuit;

- AC conductivity;

- Statistical PV parameters;

- TGA and DSC analysis; 
- Device structure;

- Photography of the devices under thermal stress

\section{AUTHOR INFORMATION}

\section{Corresponding Authors}

Dr. Narges Yaghoobi Nia

E-mail: YAGHOOBI.NIA@ing.uniroma2.it

Dr. Mojtaba Abdi-Jalebi

E-mail: $\underline{\text { m.jalebi@ucl.ac.uk }}$

Prof. Aldo Di Carlo

E-mail: aldo.dicarlo@uniroma2.it

\section{Author Contributions}

A.D.C, N.Y.N conceived the work and experiments. N.Y.N and M.Z have fabricated the small area devices and large area devices and provided data analysis with all corresponding figures. Z.Z assists N.Y.N for fabrication of small and large area devices and related IV measurements. N.Y.N, M.Z, L.A.C have fabricated the Modules and performed IV measurements with corresponding figures. M.Z performed the sealing process. N.Y.N and M.Z have performed all the damp heat tests. M.Z, N.Y.N and Z.Z have performed TPV, EIS, DARK JV, TPC and E.L assists N.Y.N for TPC, TPV measurements. N.Y.N has written the first draft of the manuscript. M.A.-J. conceived and performed PDS, IPCE, TRPL and pulsed-PL and he provided input on data interpretations. Z.A.-G performed TRPL and pulsed- PL and helped with analysis and preparation of the corresponding figure. F.U.K. collected and analysed STEM-HAADF images and STEM-EDX data and provided data analysis with corresponding figure with input from M.A.-J and G.D. G.D. and C.D. supervised F.U.K. M.M.A. and K.A. performed TGA, conducted dielectric spectroscopy on PTAA diodes, and performed impedance analysis with corresponding figures. M.Z and E.L. assist N.Y.N for the first draft preparation. N.Y.N and A.D.C. made additional interpretation of the overall results and finalized the manuscript. All authors have reviewed the manuscript carefully and agreed to the published version of the manuscript.

\section{Notes}

The authors declare no competing financial interests.

\section{ACKNOWLEDGMENT}

N.Y.N and A.D.C. gratefully acknowledge the European Union's Horizon 2020 Framework Program for funding Research and Innovation under Grant agreement no. 764047 (ESPRESSO). A.D. C. gratefully acknowledge the financial support from the Ministry of Education and Science of the Russian Federation in the framework of MegaGrant (no. 075-15-2019-872 (14.Y26.31.0027/074-02-2018-327)). L.A.C. would like to acknowledge the European Union's Horizon2020 research and innovation programme under the Marie Skłodowska -Curie grant agreement No. 764787 (MAESTRO). K.A. and M.M.A. acknowledge the Alexander von Humboldt Foundation for the funding provided in the framework of the Sofja Kovalevskaja Award, endowed by the Federal Ministry of Education and Research, Germany and the Max-Planck Institute for Polymer Research for technical support. M.A.-J. thanks Cambridge Materials Limited, Wolfson College, University of Cambridge, the Royal Society and the Engineering and Physical Sciences Research Council(EPSRC) for their funding and technical support. Z.A.- G. acknowledges funding from a Winton Studentship, and ICON Studentship from the Lloyd's Register Foundation. F.U.K. thanks the Jardine Foundation and Cambridge Trust for a doctoral scholarship. R.H.F. and M.A.-J. acknowledge support from EPSRC (grant no. EP/M005143/1). 


\section{REFERENCES}

[1] National Renewable Energy Laboratory, Best research-cell efficiencies, (2018).

[2] P. Holzhey, P. Yadav, S.H. Turren-Cruz, M. Grätzel, A. Hagfeldt, M. Saliba, A chain is as strong as its weakest link - Stability study of MAPbI3 under light and temperature, Mater. Today. (2018). https://doi.org/10.1016/j.mattod.2018.10.017.

[3] W.S. Yang, B.-W. Park, E.H. Jung, N.J. Jeon, Y.C. Kim, D.U. Lee, S.S. Shin, J. Seo, E.K. Kim, J.H. Noh, S. Il Seok, Iodide management in formamidinium-lead-halide-based perovskite layers for efficient solar cells, Science (80-. ). $356 \quad$ (2017) 1376-1379. https://doi.org/10.1126/science.aan2301.

[4] J.J. Yoo, S. Wieghold, M.C. Sponseller, M.R. Chua, S.N. Bertram, N.T.P. Hartono, J.S. Tresback, E.C. Hansen, J.-P. Correa-Baena, V. Bulović, T. Buonassisi, S.S. Shin, M.G. Bawendi, An interface stabilized perovskite solar cell with high stabilized efficiency and low voltage loss, Energy Environ. Sci. 12 (2019) 2192-2199. https://doi.org/10.1039/C9EE00751B.

[5] Q. Jiang, Y. Zhao, X. Zhang, X. Yang, Y. Chen, Z. Chu, Q. Ye, X. Li, Z. Yin, J. You, Surface passivation of perovskite film for efficient solar cells, Nat. Photonics. 13 (2019) 460-466. https://doi.org/10.1038/s41566-019-0398-2.

[6] M. Jeong, I.W. Choi, E.M. Go, Y. Cho, M. Kim, B. Lee, S. Jeong, Y. Jo, H.W. Choi, J. Lee, J.H. Bae, S.K. Kwak, D.S. Kim, C. Yang, Stable perovskite solar cells with efficiency exceeding $24.8 \%$ and $0.3-\mathrm{V}$ voltage loss, Science. $369 \quad$ (2020) 1615-1620. https://doi.org/10.1126/science.abb7167.

[7] A.M. Elseman, W. Sharmoukh, S. Sajid, P. Cui, J. Ji, S. Dou, D. Wei, H. Huang, W. Xi, L. Chu, Y. Li, B. Jiang, M. Li, Superior Stability and Efficiency Over 20\% Perovskite Solar Cells Achieved by a Novel Molecularly Engineered Rutin-AgNPs/Thiophene Copolymer, Adv. Sci. 6 (2019) 1802223. https://doi.org/10.1002/advs.201802223.

[8] X. Li, J. Yang, Q. Jiang, H. Lai, S. Li, Y. Tan, Y. Chen, S. Li, Perovskite solar cells employing an eco-friendly and low-cost inorganic hole transport layer for enhanced photovoltaic performance and operational stability, J. Mater. Chem. A. 7 (2019) 7065-7073. https://doi.org/10.1039/c9ta01499c.

[9] B. Pashaei, H. Shahroosvand, M. Ameri, E. Mohajerani, M.K. Nazeeruddin, A sequential condensation route as a versatile platform for low cost and efficient hole transport materials in perovskite solar cells, J. Mater. Chem. A. 7 (2019) 21867-21873. https://doi.org/10.1039/c9ta05121j.

[10] E.H. Jung, N.J. Jeon, E.Y. Park, C.S. Moon, T.J. Shin, T.Y. Yang, J.H. Noh, J. Seo, Efficient, stable and scalable perovskite solar cells using poly(3-hexylthiophene), Nature. 567 (2019) 511515. https://doi.org/10.1038/s41586-019-1036-3.

[11] J. Liu, Y. Wu, C. Qin, X. Yang, T. Yasuda, A. Islam, K. Zhang, W. Peng, W. Chen, L. Han, A dopant-free hole-transporting material for efficient and stable perovskite solar cells, Energy Environ. Sci. 7 (2014) 2963-2967. https://doi.org/10.1039/C4EE01589D.

[12] N.J. Jeon, H. Na, E.H. Jung, T.Y. Yang, Y.G. Lee, G. Kim, H.W. Shin, S. Il Seok, J. Lee, J. Seo, A fluorene-terminated hole-transporting material for highly efficient and stable perovskite solar cells, Nat. Energy. 3 (2018) 682-689. https://doi.org/10.1038/s41560-018-0200-6.

[13] N. Arora, M.I. Dar, A. Hinderhofer, N. Pellet, F. Schreiber, S.M. Zakeeruddin, M. Grätzel, 
Perovskite solar cells with CuSCN hole extraction layers yield stabilized efficiencies greater than 20\%, Science (80-. ). 358 (2017) 768-771. https://doi.org/10.1126/science.aam5655.

[14] Z. Hawash, L.K. Ono, Y. Qi, Recent Advances in Spiro-MeOTAD Hole Transport Material and Its Applications in Organic-Inorganic Halide Perovskite Solar Cells, Adv. Mater. Interfaces. 5 (2018) 1700623. https://doi.org/10.1002/admi.201700623.

[15] T. Leijtens, I.-K. Ding, T. Giovenzana, J.T. Bloking, M.D. McGehee, A. Sellinger, Hole Transport Materials with Low Glass Transition Temperatures and High Solubility for Application in Solid-State Dye-Sensitized Solar Cells, ACS Nano. 6 (2012) 1455-1462. https://doi.org/10.1021/nn204296b.

[16] Y. Fang, X. Wang, Q. Wang, J. Huang, T. Wu, Impact of annealing on spiro-OMeTAD and corresponding solid-state dye sensitized solar cells, Phys. Status Solidi. 211 (2014) 2809-2816. https://doi.org/10.1002/pssa.201431366.

[17] A.K. Jena, Y. Numata, M. Ikegami, T. Miyasaka, Role of spiro-OMeTAD in performance deterioration of perovskite solar cells at high temperature and reuse of the perovskite films to avoid Pb-waste, J. Mater. Chem. A. 6 (2018) 2219-2230. https://doi.org/10.1039/C7TA07674F.

[18] R.J. Kline, M.D. McGehee, E.N. Kadnikova, J. Liu, J.M.J. Fréchet, Controlling the field-effect mobility of regioregular polythiophene by changing the molecular weight, Adv. Mater. 15 (2003) 1519-1522. https://doi.org/10.1002/adma.200305275.

[19] R.J. Kline, M.D. McGehee, E.N. Kadnikova, J. Liu, J.M.J. Fréchet, M.F. Toney, Dependence of regioregular poly(3-hexylthiophene) film morphology and field-effect mobility on molecular weight, Macromolecules. 38 (2005) 3312-3319. https://doi.org/10.1021/ma047415f.

[20] A. Zen, J. Pflaum, S. Hirschmann, W. Zhuang, F. Jaiser, U. Asawapirom, J.P. Rabe, U. Scherf, D. Neher, Effect of molecular weight and annealing of poly(3-hexylthiophene)s on the performance of organic field-effect transistors, Adv. Funct. Mater. 14 (2004) 757-764. https://doi.org/10.1002/adfm.200400017.

[21] J. Cornil, D. Beljonne, J. - P. Calbert, J. - L. Brédas, Interchain Interactions in Organic $\pi$ - Conjugated Materials: Impact on Electronic Structure, Optical Response, and Charge Transport, Adv. Mater. 13 (2001) 1053-1067. https://doi.org/10.1002/15214095(200107)13:14<1053::AID-ADMA1053>3.0.CO;2-7.

[22] J.H. Bombile, M.J. Janik, S.T. Milner, Polaron formation mechanisms in conjugated polymers, Phys. Chem. Chem. Phys. 20 (2017) 317-331. https://doi.org/10.1039/c7cp04355d.

[23] J.F. Chang, J. Clark, N. Zhao, H. Sirringhaus, D.W. Breiby, J.W. Andreasen, M.M. Nielsen, M. Giles, M. Heeney, I. McCulloch, Molecular-weight dependence of interchain polaron delocalization and exciton bandwidth in high-mobility conjugated polymers, Phys. Rev. B Condens. Matter Mater. Phys. 74 (2006) 115318. https://doi.org/10.1103/PhysRevB.74.115318.

[24] N.Y. Nia, F. Matteocci, L. Cina, A. Di Carlo, High-Efficiency Perovskite Solar Cell Based on Poly(3-Hexylthiophene): Influence of Molecular Weight and Mesoscopic Scaffold Layer, ChemSusChem. 10 (2017) 3854-3860. https://doi.org/10.1002/cssc.201700635.

[25] M. Stolterfoht, P. Caprioglio, C.M. Wolff, J.A. Márquez, J. Nordmann, S. Zhang, D. Rothhardt, U. Hörmann, Y. Amir, A. Redinger, L. Kegelmann, F. Zu, S. Albrecht, N. Koch, T. Kirchartz, M. Saliba, T. Unold, D. Neher, The impact of energy alignment and interfacial recombination on the internal and external open-circuit voltage of perovskite solar cells, Energy Environ. Sci. 12 
(2019) 2778-2788. https://doi.org/10.1039/c9ee02020a.

[26] I. Lee, N. Rolston, P.-L. Brunner, R.H. Dauskardt, Hole-Transport Layer Molecular Weight and Doping Effects on Perovskite Solar Cell Efficiency and Mechanical Behavior, ACS Appl. Mater. Interfaces. 11 (2019) 23757-23764. https://doi.org/10.1021/acsami.9b05567.

[27] Y. Ko, Y. Kim, C. Lee, Y. Kim, Y. Jun, Investigation of Hole-Transporting Poly(triarylamine) on Aggregation and Charge Transport for Hysteresisless Scalable Planar Perovskite Solar Cells, ACS Appl. Mater. Interfaces. 10 (2018) 11633-11641. https://doi.org/10.1021/acsami.7b18745.

[28] Q. Zhao, R. Wu, Z. Zhang, J. Xiong, Z. He, B. Fan, Z. Dai, B. Yang, X. Xue, P. Cai, S. Zhan, X. Zhang, J. Zhang, Achieving efficient inverted planar perovskite solar cells with nondoped PTAA as a hole transport layer, Org. Electron. Physics, Mater. Appl. 71 (2019) 106-112. https://doi.org/10.1016/j.orgel.2019.05.019.

[29] N.J. Jeon, J.H. Noh, Y.C. Kim, W.S. Yang, S. Ryu, S. Il Seok, Solvent engineering for highperformance inorganic-organic hybrid perovskite solar cells, Nat. Mater. 13 (2014) 897-903. https://doi.org/10.1038/nmat4014.

[30] J. Kim, N. Park, J.S. Yun, S. Huang, M.A. Green, A.W.Y. Ho-Baillie, An effective method of predicting perovskite solar cell lifetime-Case study on planar $\mathrm{CH} 3 \mathrm{NH} 3 \mathrm{PbI} 3$ and $\mathrm{HC}(\mathrm{NH} 2$ ) 2 $\mathrm{PbI} 3$ perovskite solar cells and hole transfer materials of spiro-OMeTAD and PTAA, Sol. Energy Mater. Sol. Cells. 162 (2017) 41-46. https://doi.org/10.1016/j.solmat.2016.12.043.

[31] Y. Kim, E.H. Jung, G. Kim, D. Kim, B.J. Kim, J. Seo, Sequentially Fluorinated PTAA Polymers for Enhancing V OC of High-Performance Perovskite Solar Cells, Adv. Energy Mater. 8 (2018) 1801668. https://doi.org/10.1002/aenm.201801668.

[32] T. Bu, J. Li, F. Zheng, W. Chen, X. Wen, Z. Ku, Y. Peng, J. Zhong, Y.B. Cheng, F. Huang, Universal passivation strategy to slot-die printed $\mathrm{SnO} 2$ for hysteresis-free efficient flexible perovskite solar module, Nat. Commun. 9 (2018). https://doi.org/10.1038/s41467-018-07099-9.

[33] A. Agresti, S. Pescetelli, A.L. Palma, B. Martín-García, L. Najafi, S. Bellani, I. Moreels, M. Prato, F. Bonaccorso, A. Di Carlo, Two-Dimensional Material Interface Engineering for Efficient Perovskite Large-Area Modules, ACS Energy Lett. 4 (2019) 1862-1871. https://doi.org/10.1021/acsenergylett.9b01151.

[34] H. Chen, F. Ye, W. Tang, J. He, M. Yin, Y. Wang, F. Xie, E. Bi, X. Yang, M. Grätzel, L. Han, A solvent-and vacuum-free route to large-area perovskite films for efficient solar modules, Nature. 550 (2017) 92-95. https://doi.org/10.1038/nature23877.

[35] C.H. Chiang, J.W. Lin, C.G. Wu, One-step fabrication of a mixed-halide perovskite film for a high-efficiency inverted solar cell and module, J. Mater. Chem. A. 4 (2016) 13525-13533. https://doi.org/10.1039/c6ta05209f.

[36] F. De Rossi, J.A. Baker, D. Beynon, K.E.A. Hooper, S.M.P. Meroni, D. Williams, Z. Wei, A. Yasin, C. Charbonneau, E.H. Jewell, T.M. Watson, All Printable Perovskite Solar Modules with $198 \mathrm{~cm} 2$ Active Area and Over 6\% Efficiency, Adv. Mater. Technol. 3 (2018). https://doi.org/10.1002/admt.201800156.

[37] F. Di Giacomo, S. Shanmugam, H. Fledderus, B.J. Bruijnaers, W.J.H. Verhees, M.S. Dorenkamper, S.C. Veenstra, W. Qiu, R. Gehlhaar, T. Merckx, T. Aernouts, R. Andriessen, Y. Galagan, Up-scalable sheet-to-sheet production of high efficiency perovskite module and solar cells on 6-in. substrate using slot die coating, Sol. Energy Mater. Sol. Cells. 181 (2018) 53-59. 
https://doi.org/10.1016/j.solmat.2017.11.010.

[38] J. He, E. Bi, W. Tang, Y. Wang, X. Yang, H. Chen, L. Han, Low-Temperature Soft-CoverAssisted Hydrolysis Deposition of Large-Scale TiO2 Layer for Efficient Perovskite Solar Modules, Nano-Micro Lett. 10 (2018) 49. https://doi.org/10.1007/s40820-018-0203-7.

[39] Y. Hu, S. Si, A. Mei, Y. Rong, H. Liu, X. Li, H. Han, Stable Large-Area $(10 \times 10 \mathrm{~cm} 2)$ Printable Mesoscopic Perovskite Module Exceeding 10\% Efficiency, Sol. RRL. 1 (2017) 1600019. https://doi.org/10.1002/solr.201600019.

[40] X. Hu, Z. Huang, F. Li, M. Su, Z. Huang, Z. Zhao, Z. Cai, X. Yang, X. Meng, P. Li, Y. Wang, M. Li, Y. Chen, Y. Song, Nacre-inspired crystallization and elastic "brick-and-mortar" structure for a wearable perovskite solar module, Energy Environ. Sci. 12 (2019) 979-987. https://doi.org/10.1039/c8ee01799a.

[41] Y. Hu, Y. Chu, Q. Wang, Z. Zhang, Y. Ming, A. Mei, Y. Rong, H. Han, Standardizing Perovskite Solar Modules beyond Cells, Joule. 3 (2019) 2076-2085. https://doi.org/10.1016/j.joule.2019.08.015.

[42] Y. Jiang, M. Remeika, Z. Hu, E.J. Juarez-Perez, L. Qiu, Z. Liu, T. Kim, L.K. Ono, D.Y. Son, Z. Hawash, M.R. Leyden, Z. Wu, L. Meng, J. Hu, Y. Qi, Negligible-Pb-Waste and Upscalable Perovskite Deposition Technology for High-Operational-Stability Perovskite Solar Modules, Adv. Energy Mater. 9 (2019). https://doi.org/10.1002/aenm.201803047.

[43] N. Yaghoobi Nia, M. Zendehdel, L. Cinà, F. Matteocci, A. Di Carlo, A crystal engineering approach for scalable perovskite solar cells and module fabrication: A full out of glove box procedure, J. Mater. Chem. A. 6 (2018). https://doi.org/10.1039/c7ta08038g.

[44] Y. Jiang, L. Qiu, E.J. Juarez-Perez, L.K. Ono, Z. Hu, Z. Liu, Z. Wu, L. Meng, Q. Wang, Y. Qi, Reduction of lead leakage from damaged lead halide perovskite solar modules using self-healing polymer-based encapsulation, Nat. Energy. 4 (2019) 585-593. https://doi.org/10.1038/s41560019-0406-2.

[45] F. Matteocci, L. Cinà, F. Di Giacomo, S. Razza, A.L. Palma, A. Guidobaldi, A. D’Epifanio, S. Licoccia, T.M. Brown, A. Reale, A. Di Carlo, High efficiency photovoltaic module based on mesoscopic organometal halide perovskite, Prog. Photovoltaics Res. Appl. 24 (2016) 436-445. https://doi.org/10.1002/pip.2557.

[46] G. Grancini, C. Roldán-Carmona, I. Zimmermann, E. Mosconi, X. Lee, D. Martineau, S. Narbey, F. Oswald, F. De Angelis, M. Graetzel, M.K. Nazeeruddin, One-Year stable perovskite solar cells by 2D/3D interface engineering, Nat. Commun. 8 (2017) 1-8. https://doi.org/10.1038/ncomms 15684 .

[47] A. Priyadarshi, L.J. Haur, P. Murray, D. Fu, S. Kulkarni, G. Xing, T.C. Sum, N. Mathews, S.G. Mhaisalkar, A large area $(70 \mathrm{~cm} 2)$ monolithic perovskite solar module with a high efficiency and stability, Energy Environ. Sci. 9 (2016) 3687-3692. https://doi.org/10.1039/c6ee02693a.

[48] W. Qiu, T. Merckx, M. Jaysankar, C. Masse De La Huerta, L. Rakocevic, W. Zhang, U.W. Paetzold, R. Gehlhaar, L. Froyen, J. Poortmans, D. Cheyns, H.J. Snaith, P. Heremans, Pinholefree perovskite films for efficient solar modules, Energy Environ. Sci. 9 (2016) 484-489. https://doi.org/10.1039/c5ee03703d.

[49] L. Qiu, S. He, Y. Jiang, D.Y. Son, L.K. Ono, Z. Liu, T. Kim, T. Bouloumis, S. Kazaoui, Y. Qi, Hybrid chemical vapor deposition enables scalable and stable Cs-FA mixed cation perovskite 
solar modules with a designated area of $91.8 \mathrm{~cm} 2$ approaching $10 \%$ efficiency, J. Mater. Chem. A. 7 (2019) 6920-6929. https://doi.org/10.1039/c9ta00239a.

[50] P.S. Shen, J.S. Chen, Y.H. Chiang, M.H. Li, T.F. Guo, P. Chen, Low-Pressure Hybrid Chemical Vapor Growth for Efficient Perovskite Solar Cells and Large-Area Module, Adv. Mater. Interfaces. 3 (2016). https://doi.org/10.1002/admi.201500849.

[51] Y. Deng, X. Zheng, Y. Bai, Q. Wang, J. Zhao, J. Huang, Surfactant-controlled ink drying enables high-speed deposition of perovskite films for efficient photovoltaic modules, Nat. Energy. 3 (2018) 560-566. https://doi.org/10.1038/s41560-018-0153-9.

[52] J. Troughton, K. Hooper, T.M. Watson, Humidity resistant fabrication of $\mathrm{CH} 3 \mathrm{NH} 3 \mathrm{PbI} 3$ perovskite solar cells and modules, Nano Energy. 39 (2017) 60-68. https://doi.org/10.1016/j.nanoen.2017.06.039.

[53] M. Yang, Z. Li, M.O. Reese, O.G. Reid, D.H. Kim, S. Siol, T.R. Klein, Y. Yan, J.J. Berry, M.F.A.M. Van Hest, K. Zhu, Perovskite ink with wide processing window for scalable highefficiency solar cells, Nat. Energy. 2 (2017). https://doi.org/10.1038/nenergy.2017.38.

[54] S. Razza, F. Di Giacomo, F. Matteocci, L. Cinà, A.L. Palma, S. Casaluci, P. Cameron, A. D’Epifanio, S. Licoccia, A. Reale, T.M. Brown, A. Di Carlo, Perovskite solar cells and large area modules $(100 \mathrm{~cm} 2)$ based on an air flow-assisted PbI2 blade coating deposition process, J. Power Sources. 277 (2015) 286-291. https://doi.org/10.1016/j.jpowsour.2014.12.008.

[55] N. Yaghoobi Nia, F. Giordano, M. Zendehdel, L. Cinà, A.L. Palma, P.G. Medaglia, S.M. Zakeeruddin, M. Grätzel, A. Di Carlo, Solution-based heteroepitaxial growth of stable mixed cation/anion hybrid perovskite thin film under ambient condition via a scalable crystal engineering approach, Nano Energy. 69 (2020). https://doi.org/10.1016/j.nanoen.2019.104441.

[56] J. Li, H. Wang, X.Y. Chin, H.A. Dewi, K. Vergeer, T.W. Goh, J.W.M. Lim, J.H. Lew, K.P. Loh, C. Soci, T.C. Sum, H.J. Bolink, N. Mathews, S. Mhaisalkar, A. Bruno, Highly Efficient Thermally Co-evaporated Perovskite Solar Cells and Mini-modules, Joule. (2020). https://doi.org/10.1016/j.joule.2020.03.005.

[57] G. Bai, Z. Wu, J. Li, T. Bu, W. Li, W. Li, F. Huang, Q. Zhang, Y.B. Cheng, J. Zhong, High performance perovskite sub-module with sputtered $\mathrm{SnO} 2$ electron transport layer, Sol. Energy. 183 (2019) 306-314. https://doi.org/10.1016/j.solener.2019.03.026.

[58] T. Bu, X. Liu, J. Li, W. Li, W. Huang, Z. Ku, Y. Peng, F. Huang, Y.B. Cheng, J. Zhong, Subsized monovalent alkaline cations enhanced electrical stability for over $17 \%$ hysteresis-free planar perovskite solar mini-module, Electrochim. Acta. 306 (2019) 635-642. https://doi.org/10.1016/j.electacta.2019.03.176.

[59] K.M. Lee, C.J. Lin, B.Y. Liou, S.M. Yu, C.C. Hsu, V. Suryanarayanan, M.C. Wu, Selection of anti-solvent and optimization of dropping volume for the preparation of large area sub-module perovskite solar cells, Sol. Energy Mater. Sol. Cells. 172 (2017) 368-375. https://doi.org/10.1016/j.solmat.2017.08.010.

[60] J.S. Yeo, C.H. Lee, D. Jang, S. Lee, S.M. Jo, H.I. Joh, D.Y. Kim, Reduced graphene oxideassisted crystallization of perovskite via solution-process for efficient and stable planar solar cells with module-scales, Nano Energy. $30 \quad$ (2016) 667-676. https://doi.org/10.1016/j.nanoen.2016.10.065.

[61] F. Matteocci, L. Vesce, F.U. Kosasih, L.A. Castriotta, S. Cacovich, A.L. Palma, G. Divitini, C. 
Ducati, A. Di Carlo, Fabrication and Morphological Characterization of High-Efficiency BladeCoated Perovskite Solar Modules, ACS Appl. Mater. Interfaces. 11 (2019) 25195-25204. https://doi.org/10.1021/acsami.9b05730.

[62] A. Agresti, S. Pescetelli, A.L. Palma, A.E. Del Rio Castillo, D. Konios, G. Kakavelakis, S. Razza, L. Cinà, E. Kymakis, F. Bonaccorso, A. Di Carlo, Graphene Interface Engineering for Perovskite Solar Modules: 12.6\% Power Conversion Efficiency over $50 \mathrm{~cm} 2$ Active Area, ACS Energy Lett. 2 (2017) 279-287. https://doi.org/10.1021/acsenergylett.6b00672.

[63] N. Yaghoobi Nia, E. Lamanna, M. Zendehdel, A.L. Palma, F. Zurlo, L.A. Castriotta, A. Di Carlo, Doping Strategy for Efficient and Stable Triple Cation Hybrid Perovskite Solar Cells and Module Based on Poly(3-hexylthiophene) Hole Transport Layer, Small. 15 (2019). https://doi.org/10.1002/smll.201904399.

[64] J.M. Marin-Beloqui, L. Lanzetta, E. Palomares, Decreasing Charge Losses in Perovskite Solar Cells Through mp-TiO2/MAPI Interface Engineering, Chem. Mater. 28 (2016) 207-213. https://doi.org/10.1021/acs.chemmater.5b03902.

[65] L. Zhang, Device physics of perovskite solar cells, Iowa State University, Digital Repository, 2017. https://doi.org/10.31274/etd-180810-5932.

[66] X. Zhu, D. Yang, R. Yang, B. Yang, Z. Yang, X. Ren, J. Zhang, J. Niu, J. Feng, S. Liu, Superior stability for perovskite solar cells with $20 \%$ efficiency using vacuum co-evaporation, Nanoscale. 9 (2017) 12316-12323. https://doi.org/10.1039/c7nr04501h.

[67] R.H. Bube, Trap Density Determination by Space-Charge-Limited Currents, J. Appl. Phys. 33 (1962) 1733-1737. https://doi.org/10.1063/1.1728818.

[68] M. Alsari, A.J. Pearson, J.T.W. Wang, Z. Wang, A. Montisci, N.C. Greenham, H.J. Snaith, S. Lilliu, R.H. Friend, Degradation Kinetics of Inverted Perovskite Solar Cells, Sci. Rep. 8 (2018) 5977. https://doi.org/10.1038/s41598-018-24436-6.

[69] S. Wheeler, D. Bryant, J. Troughton, T. Kirchartz, T. Watson, J. Nelson, J.R. Durrant, Transient Optoelectronic Analysis of the Impact of Material Energetics and Recombination Kinetics on the Open-Circuit Voltage of Hybrid Perovskite Solar Cells, J. Phys. Chem. C. 121 (2017) 1349613506. https://doi.org/10.1021/acs.jpcc.7b02411.

[70] M. Ameri, E. Mohajerani, M. Ghafarkani, N. Safari, S.A. Alavi, The investigation of the unseen interrelationship of grain size, ionic defects, device physics and performance of perovskite solar cells, J. Phys. D. Appl. Phys. 52 (2019) 125501. https://doi.org/10.1088/1361-6463/AAFEA9.

[71] M. Ameri, M. Ghaffarkani, R.T. Ghahrizjani, N. Safari, E. Mohajerani, Phenomenological morphology design of hybrid organic-inorganic perovskite solar cell for high efficiency and less hysteresis, Sol. Energy Mater. Sol. Cells. $205 \quad$ (2020) 110251. https://doi.org/10.1016/j.solmat.2019.110251.

[72] J.M. Richter, M. Abdi-Jalebi, A. Sadhanala, M. Tabachnyk, J.P.H. Rivett, L.M. Pazos-Outón, K.C. Gödel, M. Price, F. Deschler, R.H. Friend, Enhancing photoluminescence yields in lead halide perovskites by photon recycling and light out-coupling, Nat. Commun. 7 (2016) 1-8. https://doi.org/10.1038/ncomms 13941.

[73] M. Abdi-Jalebi, M.I. Dar, S.P. Senanayak, A. Sadhanala, Z. Andaji-Garmaroudi, L.M. PazosOutón, J.M. Richter, A.J. Pearson, H. Sirringhaus, M. Grätzel, R.H. Friend, Charge extraction via graded doping of hole transport layers gives highly luminescent and stable metal halide 
perovskite devices, Sci. Adv. 5 (2019) eaav2012. https://doi.org/10.1126/sciadv.aav2012.

[74] M. Abdi-Jalebi, M.I. Dar, A. Sadhanala, S.P. Senanayak, F. Giordano, S.M. Zakeeruddin, M. Grätzel, R.H. Friend, Impact of a Mesoporous Titania-Perovskite Interface on the Performance of Hybrid Organic-Inorganic Perovskite Solar Cells, J. Phys. Chem. Lett. 7 (2016) 3264-3269. https://doi.org/10.1021/acs.jpclett.6b01617.

[75] M. Abdi-Jalebi, M.I. Dar, S.P. Senanayak, A. Sadhanala, Z. Andaji-Garmaroudi, L.M. PazosOutón, J.M. Richter, A.J. Pearson, H. Sirringhaus, M. Grätzel, R.H. Friend, Charge extraction via graded doping of hole transport layers gives highly luminescent and stable metal halide perovskite devices, Sci. Adv. 5 (2019) eaav2012. https://doi.org/10.1126/sciadv.aav2012.

[76] A. Abate, D.J. Hollman, J. Teuscher, S. Pathak, R. Avolio, G. D’Errico, G. Vitiello, S. Fantacci, H.J. Snaith, Protic ionic liquids as p-dopant for organic hole transporting materials and their application in high efficiency hybrid solar cells, J. Am. Chem. Soc. 135 (2013) 13538-13548. https://doi.org/10.1021/ja406230f.

[77] S.C. Tjong, Y.W. Mai, Physical properties and applications of polymer nanocomposites, Woodhead Pub, 2010.

[78] S.L. Pittelli, M. De Keersmaecker, J.F. Ponder, A.M. Österholm, M.A. Ochieng, J.R. Reynolds, Structural effects on the charge transport properties of chemically and electrochemically doped dioxythiophene polymers, J. Mater. Chem. C. 8 (2020) 683-693. https://doi.org/10.1039/c9tc05697a.

[79] M.S. Kim, J. Perry Iv, T.C.M. Julien, E. Marangon, C. Manouat, J.F. Eubank, J.P. Harmon, Zeroperiodic metal-organic material, organic polymer composites: tuning properties of methacrylate polymers via dispersion of dodecyloxy-decorated $\mathrm{Cu}-\mathrm{BDC}$ nanoballs, J. Mater. Chem. A. 3 (2015) 13215-13225. https://doi.org/10.1039/c4ta06647b.

[80] The concept of 'doping' of conducting polymers: the role of reduction potentials, Philos. Trans. R. Soc. London. Ser. A, Math. Phys. Sci. 314 (1985) 3-15. https://doi.org/10.1098/rsta.1985.0004.

[81] S. Cacovich, F. Matteocci, M. Abdi-Jalebi, S.D. Stranks, A. Di Carlo, C. Ducati, G. Divitini, Unveiling the Chemical Composition of Halide Perovskite Films Using Multivariate Statistical Analyses, ACS Appl. Energy Mater. 1 (2018) 7174-7181. https://doi.org/10.1021/acsaem.8b01622.

[82] K.T. Cho, S. Paek, G. Grancini, C. Roldán-Carmona, P. Gao, Y. Lee, M.K. Nazeeruddin, Highly efficient perovskite solar cells with a compositionally engineered perovskite/hole transporting material interface, Energy Environ. Sci. 10 (2017) 621-627. https://doi.org/10.1039/c6ee03182j.

[83] N. Yaghoobi Nia, M. Méndez, B. Paci, A. Generosi, A. Di Carlo, E. Palomares, Analysis of The Efficiency Losses in Hybrid Perovskite/PTAA Solar Cells with Different Molecular Weight: Morphology vs Kinetics, ACS Appl. Energy Mater. (2020). https://doi.org/10.1021/acsaem.0c00956.

[84] W. Yang, Z. Luo, R. Sun, J. Guo, T. Wang, Y. Wu, W. Wang, J. Guo, Q. Wu, M. Shi, H. Li, C. Yang, J. Min, Simultaneous enhanced efficiency and thermal stability in organic solar cells from a polymer acceptor additive, Nat. Commun. 11 (2020) 1-10. https://doi.org/10.1038/s41467-02014926-5.

[85] L.A. Ribeiro, W.F. Da Cunha, P.H. De Oliveria Neto, R. Gargano, G.M. E Silva, Effects of 
temperature and electric field induced phase transitions on the dynamics of polarons and bipolarons, New J. Chem. 37 (2013) 2829-2836. https://doi.org/10.1039/c3nj00602f.

[86] K. Król-Morkisz, K. Pielichowska, Thermal Decomposition of Polymer Nanocomposites With Functionalized Nanoparticles, in: Polym. Compos. with Funct. Nanoparticles, Elsevier, 2019: pp. 405-435. https://doi.org/10.1016/b978-0-12-814064-2.00013-5.

[87] X. Yang, Z. Zhong, Y. Huang, The effect of PEG molecular weights on the thermal stability and dissolution behaviors of griseofulvin-PEG crystalline inclusion complexes, Int. J. Pharm. 508 (2016) 51-60. https://doi.org/10.1016/j.ijpharm.2016.05.014.

[88] R. Ghosh, C.M. Pochas, F.C. Spano, Polaron Delocalization in Conjugated Polymer Films, J. Phys. Chem. C. 120 (2016) 11394-11406. https://doi.org/10.1021/acs.jpcc.6b02917.

[89] S.T. Hoffmann, F. Jaiser, A. Hayer, H. Bässler, T. Unger, S. Athanasopoulos, D. Neher, A. Köhler, How Do Disorder, Reorganization, and Localization Influence the Hole Mobility in Conjugated Copolymers?, J. Am. Chem. Soc. 135 (2013) 1772-1782. https://doi.org/10.1021/ja308820j.

[90] B.B.Y. Hsu, C.M. Cheng, C. Luo, S.N. Patel, C. Zhong, H. Sun, J. Sherman, B.H. Lee, L. Ying, M. Wang, G. Bazan, M. Chabinyc, J.L. Brédas, A. Heeger, The Density of States and the Transport Effective Mass in a Highly Oriented Semiconducting Polymer: Electronic Delocalization in 1D, Adv. Mater. $27 \quad$ (2015) 7759-7765. https://doi.org/10.1002/adma.201502820.

[91] T.J. Aubry, J.C. Axtell, V.M. Basile, K.J. Winchell, J.R. Lindemuth, T.M. Porter, J. Liu, A.N. Alexandrova, C.P. Kubiak, S.H. Tolbert, A.M. Spokoyny, B.J. Schwartz, Dodecaborane- Based Dopants Designed to Shield Anion Electrostatics Lead to Increased Carrier Mobility in a Doped Conjugated Polymer, Adv. Mater. 31 (2019) 1805647. https://doi.org/10.1002/adma.201805647.

[92] K.T. Munson, E.R. Kennehan, G.S. Doucette, J.B. Asbury, Dynamic Disorder Dominates Delocalization, Transport, and Recombination in Halide Perovskites, Chem. 4 (2018) 2826-2843. https://doi.org/10.1016/j.chempr.2018.09.001.

[93] A.L. Palma, F. Matteocci, A. Agresti, S. Pescetelli, E. Calabro, L. Vesce, S. Christiansen, M. Schmidt, A. Di Carlo, Laser-Patterning Engineering for Perovskite Solar Modules With 95\% Aperture Ratio, IEEE J. Photovoltaics. $7 \quad$ (2017) 1674-1680. https://doi.org/10.1109/JPHOTOV.2017.2732223.

[94] H. Booth, Laser processing in industrial solar module manufacturing, J. Laser Micro Nanoeng. 5 (2010) 183-191. https://doi.org/10.2961/jlmn.2010.03.0001.

[95] F.U. Kosasih, C. Ducati, Characterising degradation of perovskite solar cells through in-situ and operando electron microscopy, Nano Energy. $47 \quad$ (2018) 243-256. https://doi.org/10.1016/j.nanoen.2018.02.055.

[96] F.J. De la Peña, V.T. Fauske, P. Burdet, T. Ostasevicius, M. Sarahan, M. Nord, J.A. Taillon, D. Johnstone, K.E. MacArthur, A. Eljarrat, S. Mazzuco, J. Caron, T. Furnival, M. Walls, E. Prestat, G. Donval, B. Martineau, L.F. Zagonel, P. Jokubauskas, T. Aarholt, A. Garmannslund, I. Iyengar, Machine Learning - Hyperspy 1.5.2 documentation, Hyperspy 1.5.2 Doc. (2019). https://doi.org/10.5281/zenodo.3396791. 


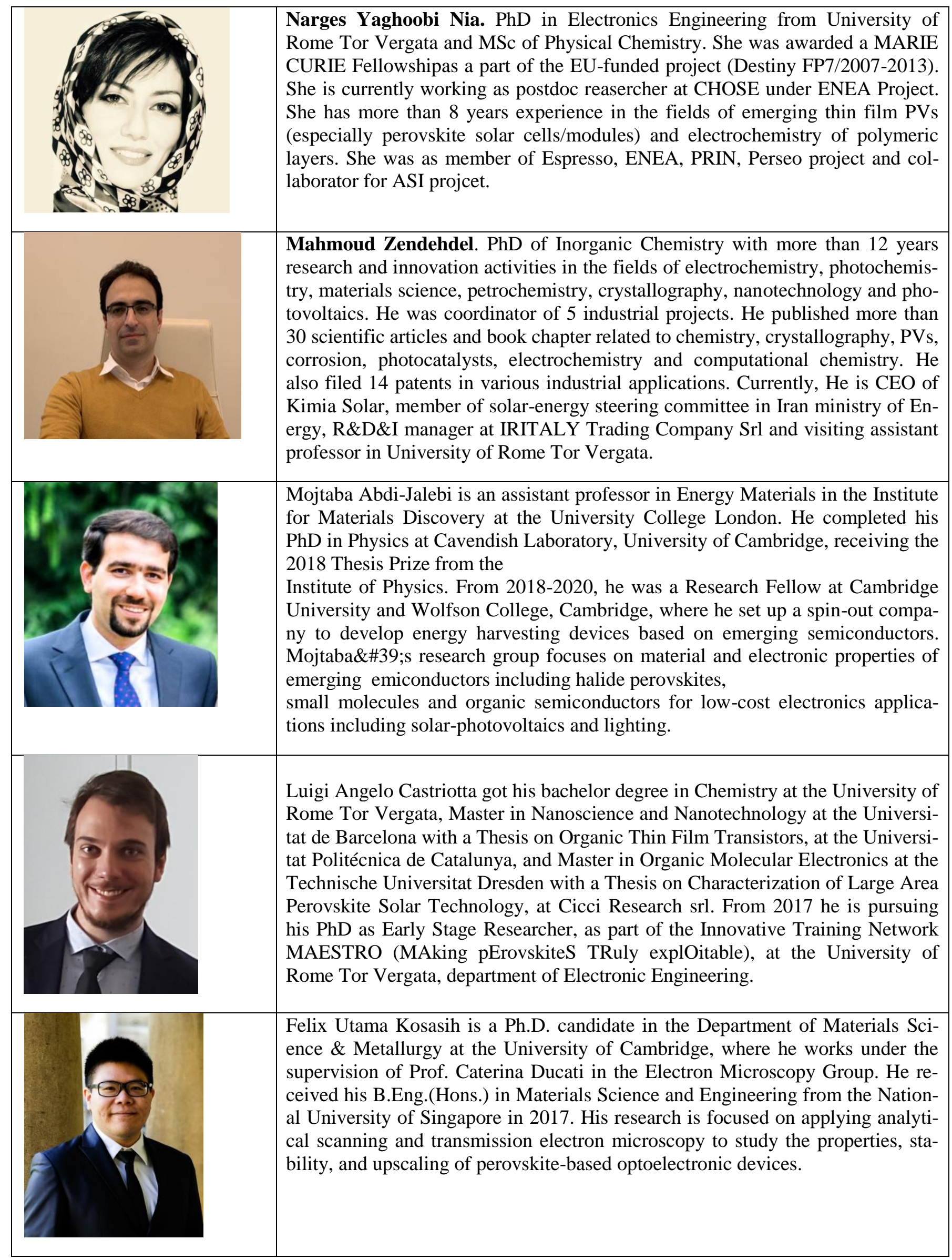




\begin{tabular}{|c|c|}
\hline & $\begin{array}{l}\text { Enrico Lamanna received his Master's degree in Electronics Engineering from } \\
\text { the University of Rome "Tor Vergata" in } 2016 \text { and completed his PhD in } 2020 \\
\text { in the same institution. His research interests have involved perovskite solar cells } \\
\text { and perovskite/silcon tandem devices. He is currently pursuing a career in the } \\
\text { field of photovoltaics on solar inverters and PV systems. }\end{array}$ \\
\hline & $\begin{array}{l}\text { "MOHAMMAD MAHDI ABOLHASANI received the Ph.D. degree in polymer } \\
\text { engineering from Amirkabir University of Technology, Tehran, Iran.Then, he } \\
\text { joined the University of Kashan, Iran, as an Assistant Professor. His work at } \\
\text { Kashan was focused on the investigation of piezoelectric performance of PVDF } \\
\text { films and fibers. In } 2014 \text {, he did a Postdoctoral with Deakin University, Austral- } \\
\text { ia. In } 2016 \text {, he received a fellowship from the Alexander von Humboldt Founda- } \\
\text { tion for a project on } \\
\text { high-K ferroelectric polymers for energy storage applications. He is currently a } \\
\text { Postdoctoral Researcher with Max-Planck institute for polymer research, Ger- } \\
\text { many." }\end{array}$ \\
\hline & $\begin{array}{l}\text { Zhaoxiang Zheng, A new graduate of the University of Rome Tor Vergata, com- } \\
\text { pleted his master's degree in electronic engineering in 2010. To realize the ex- } \\
\text { periments for his master's thesis, which concerns the application of new materi- } \\
\text { als in perovskite solar cells, Zhaoxiang Zheng has been working at the laboratory } \\
\text { C.H.O.S.E for ten months with the supervisor Dr. Narges Yaghoobi Nia and pro- } \\
\text { fessor Aldo Di Carlo. Now He works in AZ Service as a railway signalling engi- } \\
\text { neer. }\end{array}$ \\
\hline & $\begin{array}{l}\text { Zahra Andaji-Garmaroudi is a PhD researcher in the Cavendish Laboratory at } \\
\text { the University of Cambridge, and a member of St John's College, Cambridge. } \\
\text { She has been awarded Winton scholarship and ICON studentship from the } \\
\text { Lloyd's Register Foundation for her PhD studies under the supervision of Dr } \\
\text { Sam Stranks and Prof. Richard Friend. Her research and work experience have } \\
\text { been on studying micro- and macro-scale optical properties ofperovskite mate- } \\
\text { rials, and innovations that could help to boost the efficiency and stability of per- } \\
\text { ovskite devices. }\end{array}$ \\
\hline IIIA & $\begin{array}{l}\text { Kamal Asadi is a professor at the Department of Physics at the University of } \\
\text { Bath, UK. He received his PhD in physics from the University of Groningen, the } \\
\text { Netherlands, in } 2010 \text {. He joined Philips Research subsequently and worked on } \\
\text { photonic materials and devices. In } 2013 \text { he moved to the Max Planck Institute } \\
\text { for Polymer Research, where he received the Sofja Kovalevskaja Award from } \\
\text { the Alexander von Humboldt Foundation, to establish his research group. His } \\
\text { research interests include physics of electroactive, multiferroic soft materials and } \\
\text { devices thereof. He has co-authored about } 70 \text { peer-refereed papers and is holder } \\
\text { of } 8 \text { patents. }\end{array}$ \\
\hline
\end{tabular}




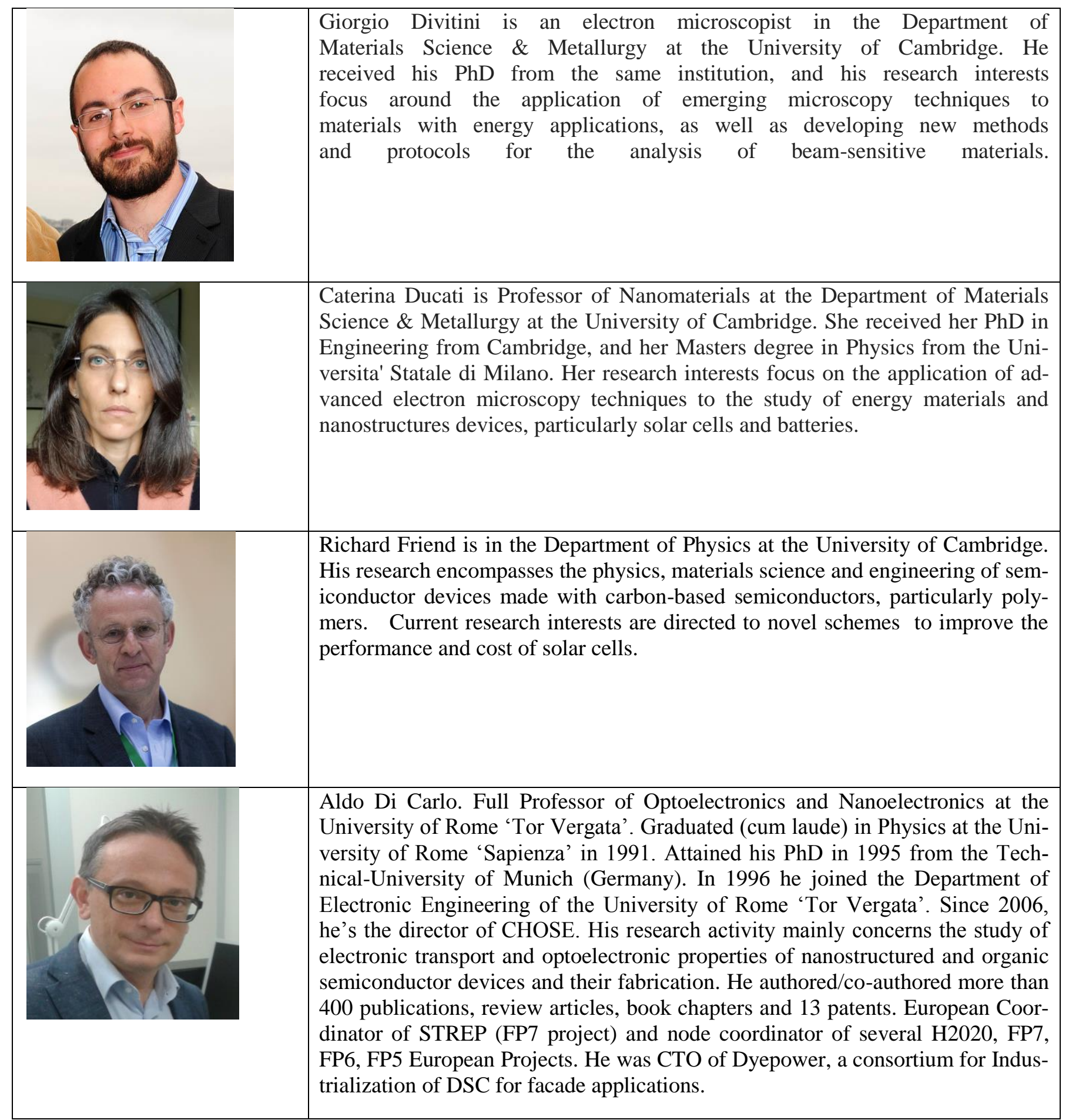


Click here to access/download Supporting Information SI_PTAA-polarons_manuscript_Nano Energy-Rev24.docx 


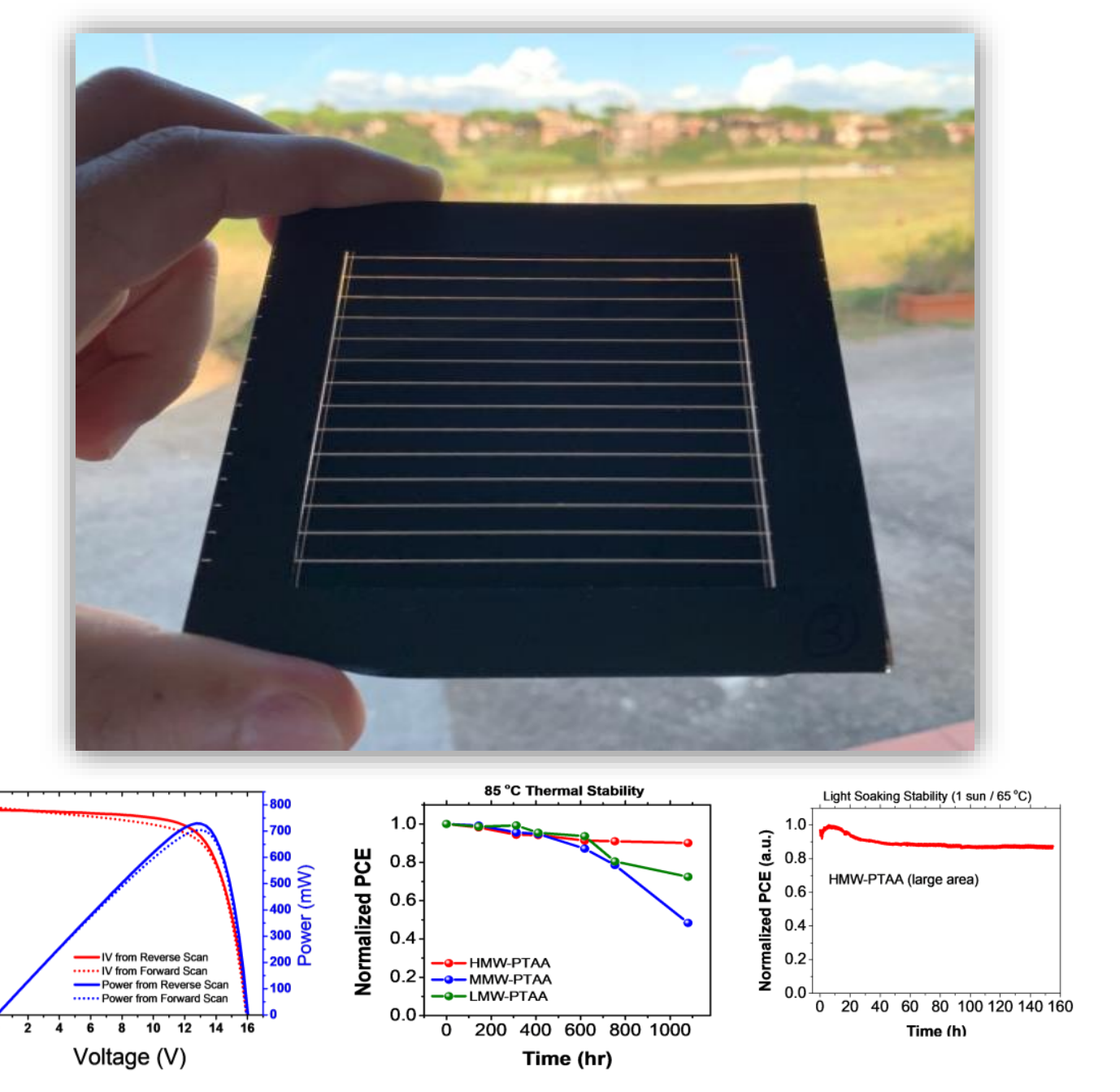




\section{Declaration of interests}

$\checkmark$ The authors declare that they have no known competing financial interests or personal relationships that could have appeared to influence the work reported in this paper.

$\square$ The authors declare the following financial interests/personal relationships which may be considered as potential competing interests:

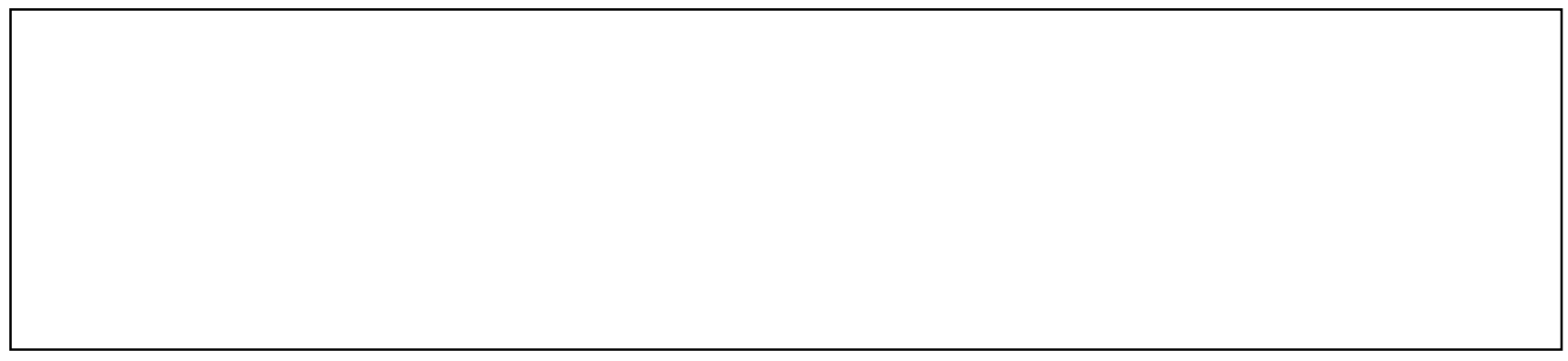




\section{Author Contributions}

A.D.C, N.Y.N conceived the work and experiments. N.Y.N and M.Z have fabricated the small area devices and large area devices and provided data analysis with all corresponding figures. Z.Z assists N.Y.N for fabrication of small and large area devices and related IV measurements. N.Y.N, M.Z, L.A.C have fabricated the Modules and performed IV measurements with corresponding figures. M.Z performed the sealing process. N.Y.N and M.Z have performed all the damp heat tests. M.Z, N.Y.N and Z.Z have performed TPV, EIS, DARK JV, TPC and E.L assists N.Y.N for TPC, TPV measurements. N.Y.N has written the first draft of the manuscript. M.A.-J. conceived and performed PDS, IPCE, TRPL and pulsedPL and he provided input on data interpretations. Z.A.-G performed TRPL and pulsed- PL and helped with analysis and preparation of the corresponding figure. F.U.K. collected and analysed STEM-HAADF images and STEM-EDX data and provided data analysis with corresponding figure with input from M.A.-J and G.D. G.D. and C.D. supervised F.U.K. M.M.A. and K.A. performed TGA, conducted dielectric spectroscopy on PTAA diodes, and performed impedance analysis with corresponding figures. M.Z and E.L. assist N.Y.N for the first draft preparation. N.Y.N and A.D.C. made additional interpretation of the overall results and finalized the manuscript. All authors have reviewed the manuscript carefully and agreed to the published version of the manuscript. 